\title{
Efficacy of Radiofrequency Neurotomy in Chronic Low Back Pain: A Systematic Review and Meta-Analysis
}

\author{
Rajesh N Janapala (D) \\ Laxmaiah Manchikanti ${ }^{2-4}$ \\ Mahendra R Sanapati (iD) ${ }^{5,6}$ \\ Srinivasa Thota ${ }^{5}$ \\ Alaa Abd-Elsayed ${ }^{7}$ \\ Alan D Kaye ${ }^{8,9}$ \\ Joshua A Hirsch ${ }^{10}$
}

'School of Medicine and Health Sciences, George Washington University, Washington, DC, USA; ${ }^{2}$ Pain Management Centers of America, Paducah, KY, USA; ${ }^{3}$ Anesthesiology and Perioperative Medicine, University of Louisville, Louisville, KY, USA;

${ }^{4}$ Department of Anesthesiology, School of Medicine, LSU Health Sciences Center, Shreveport, LA, USA; ${ }^{5}$ Pain Management Centers of America, Evansville, IN, USA; ${ }^{6}$ Anesthesiology and Research, School of Medicine, LSU Health Sciences Center, Shreveport, LA, USA; ${ }^{7}$ UW Health Pain Services, and Anesthesiology, University of Wisconsin School of Medicine and Public Health, Madison, WI, USA; ${ }^{8}$ Departments of Anesthesiology and Pharmacology, Toxicology, and Neurosciences, LSU Health Sciences Center, Shreveport, LA, USA; ${ }^{9}$ Ochsner Shreveport Hospital and Pain Clinic FeistWeiller Cancer Center, Shreveport, LA, USA; ${ }^{10}$ Neurointerventional Radiology and Spine, Massachusetts General Hospital and Harvard Medical School, Boston, MA, USA
Correspondence: Laxmaiah Manchikanti Pain Management Centers of America, 67 Lakeview Drive, Paducah, KY, 4200I, USA Tel +I 2705548373

Fax + I 2705548987

Email drIm@thepainmd.com
Purpose: The objective of the systematic review and meta-analysis is to evaluate the efficacy of radiofrequency neurotomy as a therapeutic lumbar facet joint intervention.

Patients and Methods: Utilizing the Preferred Reporting Items for Systematic Reviews and Meta-Analyses (PRISMA) checklist, a systematic review and meta-analysis was performed. A comprehensive literature search of multiple data sources from 1966 to September 2020 including manual searches of bibliography of known review articles was performed. The inclusion criteria were based on the selection of patients with chronic low back pain with diagnosis confirmed based on controlled diagnostic blocks and with the publication of at least 6 months of results of appropriate outcome parameters. Quality assessment of the trials was performed with Cochrane review criteria and interventional pain management techniques-quality appraisal of reliability and risk of bias assessment (IPM-QRB). The level of evidence of effectiveness is classified at five levels ranging from Level I to Level V. The primary outcome measure was a significant reduction in pain, eg, short term (up to 6 months) and long term (more than 6 months). The secondary outcome measure was an improvement in functional status.

Results: A total of 12 randomized controlled trials (RCTs) met the inclusion criteria for evaluating the efficacy of lumbar radiofrequency neurotomy. Radiofrequency neurotomy showed Level II evidence for efficacy for both the short term and long term.

Conclusion: This systematic review of the assessment of the efficacy of radiofrequency neurotomy in managing chronic low back pain was based on the inclusion of 12 RCTs with a diagnostic block and at least 6 months of follow-up results that showed Level II evidence for both short-term and long-term improvement.

Keywords: diagnostic facet joint nerve blocks, facet joint pain, facet joint nerve blocks, randomized trials, radiofrequency neurotomy, systematic review, meta-analysis

\section{Introduction}

Chronic axial low back pain, with or without extremity pain is one of the major causes of disability and escalating health care costs. ${ }^{1-7}$ In fact, morbidity and chronic disability now account for nearly half of the US health burden, despite substantial progress and improvement in overall health. ${ }^{6,7}$ In addition, among the 30 leading diseases and injuries contributing to years lives with disability in 2010 in the United States, low back pain ranked number one. Further, Dieleman et al ${ }^{1,2}$ showed an escalating spending pattern of low back and neck pain increasing from $\$ 87.6$ billion in 2013 to $\$ 134.5$ billion in 2016 , with more than $53.5 \%$ increase between 2013 and 2016. 
Chronic persistent low back pain lasting longer than 1 year is reported in $25 \%$ to $60 \%$ of the patients. ${ }^{3-5}$ Overall prevalence of low back pain over a period of 1 year time frame ranged from $22 \%$ to $65 \%$ with an estimated lifetime occurrence of $11 \%$ to $84 \% .^{3,4}$ Among the multiple modalities utilized in managing facet joint pain, interventional techniques with facet joint interventions have been shown to be critically important with continued ongoing discussions on effectiveness, indications and medical necessity, selection of patients for therapeutic interventions, and finally utilization patterns with extensive literature. ${ }^{3,4,8}$

In addition, the COVID-19 pandemic and the opioid epidemic have affected all aspects of human life, especially those of chronic pain sufferers. ${ }^{3,4,17,22-28}$ The pandemic has resulted in reduced access with modifications in treatment modalities, with increased psychological stressors, and suffering. ${ }^{4,17,22-28}$ The use of interventional techniques for the treatment of spinal pain increased exponentially until 2009, at which point utilization began to decrease. ${ }^{8-12}$ Among these, facet joint interventions showed an overall $1.9 \%$ annual increase from 2009 to 2018 compared to $17 \%$ annual increases from 2000 to 2009. ${ }^{8,9,11}$ The analysis of expenditures for facet joint interventions in Medicare population ${ }^{11}$ also showed an increase in expenditures of $79 \%$ from 2009 to 2018 in the form of total costs for facet joint interventions; however, the inflation-adjusted costs with 2018 US dollars showed an overall increase of $53 \%$ with an annual increase of $4.9 \%$. Further, lumbar facet joint injection procedures increased by $37 \%$ from 2009 to 2018, whereas lumbar radiofrequency neurotomy procedures increased by $169 \%$. Compared to the Medicare population which increased by $30.1 \%$ from 2009 to 2018, the total number of patients undergoing facet joint interventions increased by $65.1 \%$ with an annual increase rate of $5.7 \%$. In contrast, epidural procedures ${ }^{12}$ showed a decrease of inflationadjusted costs overall 2\%, whereas prior to inflation adjustment, total expenditures increased by $14.6 \%$ or an annual increase of $1.5 \%$. Further, the number of patient visits and services demonstrated a decline for epidural procedures compared to Medicare growth of population, in contrast to facet joint interventions. In addition, expenditures of epidural interventions showed declines. ${ }^{12}$

Significant debate in reference to effectiveness and efficacy, utilization patterns, and indications and medical necessity of interventional techniques in general and facet joint interventions in particular, including radiofrequency neurotomy procedures continues among patients, clinicians, researchers, and payors. ${ }^{3,4,8-12,18-22,28-37}$

Advanced diagnostic techniques like imaging and controlled diagnostic blocks point to multiple structures including facet joints, sacroiliac joints, intervertebral discs, and nerve roots as a possible origin of chronic low back pain. ${ }^{3,38-47}$ The diagnosis of a lumbar facet joint as the cause of chronic pain cannot be accurately established by history, physical, or imaging alone. ${ }^{3,38-47}$ The diagnosis by controlled diagnostic blocks has been shown to be reasonably accurate. ${ }^{3,38-40,46,47}$ However, the prevalence of "pure" lumbar zygapophysial joint pain in patients with chronic low back pain with placebo controlled diagnostic blocks and $100 \%$ pain relief as the criterion standard has been shown to be $15 \%$, with acute pain model. ${ }^{45}$ In this manuscript, the authors have excluded any patients who have had longer relief than a few hours. In contrast, with a philosophical paradigm shift from an acute to a chronic pain model, Manchikanti et $\mathrm{al}^{46}$ have shown a prevalence rate of $34.1 \%$ and false-positive rate of $49.8 \%$ in chronic low back pain, utilizing controlled comparative local anesthetic blocks with a criterion standard of $80 \%$ pain relief. Currently, intraarticular injections, facet joint nerve blocks, and radiofrequency neurotomy are used for therapeutic management. ${ }^{3,39,40}$ However, the evidence continues to be variable with discordant opinions in systematic reviews. ${ }^{3,39,40,48-50}$

This systematic review and meta-analysis of randomized controlled trials (RCTs) of radiofrequency neurotomy in managing chronic low back pain is sought to provide updated evidence.

\section{Methods}

A systematic review and meta-analysis was performed based on methodological and reporting quality of systematic reviews as described by Preferred Reporting Items for Systematic Reviews and Meta-Analyses (PRISMA). ${ }^{51,52}$

The objective of this systematic review and meta-analysis, therefore was to assess the efficacy and effectiveness of radiofrequency thermoneurolysis in managing chronic low back pain of facet joint origin.

\section{Studies Included}

Randomized controlled trials (RCTs).

\section{Participants Included}

Patients with low back pain for at least 3 months' duration. Studies with inadequate or lack of response to 
conservative therapies including non-steroidal anti-inflammatory drugs (NSAIDs), exercise regimens, physical therapy, and other conservative therapies and at least 6 months of follow-up were included. Studies with inclusion of acute causes of low back pain such as trauma, fractures, malignancies were excluded. Patients diagnosed with a single or double diagnostic block were included.

\section{Interventions Included}

Radiofrequency neurotomy performed under radiological imaging (fluoroscopy, computed tomography (CT), or magnetic resonance imaging (MRI)) were included while blind and ultrasound-guided interventions were excluded.

\section{Outcome Measures Included}

The primary outcome measure was pain relief. The secondary outcome measure was an improvement in functional status. The outcomes of less than 6 months of management were considered short term and 6 months or longer were considered long term.

\section{Literature Search}

A comprehensive literature search was conducted to include randomized control trials published from all countries and in all languages. Searches were performed from the following sources without language restrictions.

1. PubMed from 1966 https://pubmed.ncbi.nlm.nih. gov/

2. Cochrane Library https://www.cochranelibrary.com/

3. Google Scholar https://scholar.google.com/

4. US National Guideline Clearinghouse (NGC) https://www.ahrq.gov/gam/index.html

5. Clinical Trials https://www.clinicaltrials.gov/

6. Previous systematic reviews and cross-references

7. All other sources including non-indexed journals and abstracts

The search period was from 1966 through September 2020.

\section{Search Strategy}

The search strategy emphasized chronic low back pain treated with lumbar facet joint interventions. The search terms included: pain) OR chronic back pain) OR facet joint pain) OR lumbosciatic pain) OR postlaminectomy) OR lumbar surgery syndrome) OR zygapophysial)) AND ((((((facet joint)
OR zygapophyseal) OR zygapophysial) OR medial branch block OR intraarticular injection OR radiofrequency neurotomy) OR radiofrequency ablation.

\section{Inclusion and Exclusion Criteria}

RCTs studying radiofrequency neurotomy with at least 6 months of follow-up were included in this study. No observational studies were included. Only the trials with appropriate diagnosis established by at least one diagnostic block were included. Studies without an appropriate diagnosis, non-randomized studies, non-systematic reviews, case series, and case reports were excluded.

\section{Data Collection and Analysis}

Two review authors independently, established search criteria, searched the literature, and extracted data from the selected studies. Disagreements between the two reviewer authors were resolved by a third author.

\section{Methodological Quality Assessment}

RCTs were assessed for their quality or risk of bias methodologically with Cochrane review criteria (Table 1$)^{53}$ and Interventional Pain Management techniques-Quality Appraisal of reliability and Risk of Bias Assessment (IPM-QRB) (Table 2). ${ }^{54}$

\section{Risk of Bias of Individual Studies}

Trials that met the inclusion criteria and scored at least 9 of 13 using Cochrane review criteria were considered high quality, while trials scoring 5-8 were considered of moderate quality. Trials that scored less than 5 were considered of low quality and were excluded from the analysis.

Trials meeting the inclusion criteria were also assessed with IPM-QRB criteria. ${ }^{54}$ Studies scoring 32-48 were considered of high quality, those scored 16-31 were of moderate quality and those that scored below 16 were considered of low quality and were excluded from the analysis.

Methodological quality of the trials was assessed by two authors, independently in an unblinded manner. If a discrepancy occurred, a third author was involved to resolve the conflict. When an issue of conflict of interest was raised in reviewing the manuscript (regarding authorship), the involved authors were not allowed to review those manuscripts for quality assessment. 
Table I Sources of Risk of Bias and Cochrane Review Rating System

\begin{tabular}{|c|c|c|c|}
\hline $\begin{array}{l}\text { Bias } \\
\text { Domain }\end{array}$ & \multicolumn{2}{|r|}{ Source of Bias } & $\begin{array}{l}\text { Possible } \\
\text { Answers }\end{array}$ \\
\hline \multirow[t]{2}{*}{ Selection } & \multirow[t]{2}{*}{$\begin{array}{l}\text { (I) Was the method of randomization } \\
\text { adequate? }\end{array}$} & $\begin{array}{l}\text { A random (unpredictable) assignment sequence. Examples of adequate } \\
\text { methods are coin toss (for studies with } 2 \text { groups), rolling a dice (for } \\
\text { studies with } 2 \text { or more groups), drawing of balls of different colors, } \\
\text { drawing of ballots with the study group labels from a dark bag, } \\
\text { computer-generated random sequence, preordered sealed envelopes, } \\
\text { sequentially ordered vials, telephone call to a central office, and } \\
\text { preordered list of treatment assignments. }\end{array}$ & \multirow[t]{2}{*}{$\begin{array}{l}\text { Yes/No/ } \\
\text { Unsure }\end{array}$} \\
\hline & & $\begin{array}{l}\text { Examples of inadequate methods are: alternation, birth date, social } \\
\text { insurance/security number, date in which they are invited to } \\
\text { participate in the study, and hospital registration number. }\end{array}$ & \\
\hline Selection & (2) Was the treatment allocation concealed? & $\begin{array}{l}\text { Assignment generated by an independent person not responsible for } \\
\text { determining the eligibility of the patients. This person has no } \\
\text { information about the persons included in the trial and has no } \\
\text { influence on the assignment sequence or on the decision about } \\
\text { eligibility of the patient. }\end{array}$ & $\begin{array}{l}\text { Yes/No/ } \\
\text { Unsure }\end{array}$ \\
\hline Performance & $\begin{array}{l}\text { (3) Was the patient blinded to the } \\
\text { intervention? }\end{array}$ & $\begin{array}{l}\text { Index and control groups are indistinguishable for the patients or if the } \\
\text { success of blinding was tested among the patients and it was successful. }\end{array}$ & $\begin{array}{l}\text { Yes/ } \mathrm{No} / \\
\text { Unsure }\end{array}$ \\
\hline Performance & $\begin{array}{l}\text { (4) Was the care provider blinded to the } \\
\text { intervention? }\end{array}$ & $\begin{array}{l}\text { Index and control groups are indistinguishable for the care providers } \\
\text { or if the success of blinding was tested among the care providers and it } \\
\text { was successful. }\end{array}$ & $\begin{array}{l}\text { Yes/No/ } \\
\text { Unsure }\end{array}$ \\
\hline \multirow[t]{6}{*}{ Detection } & \multirow[t]{6}{*}{$\begin{array}{l}\text { (5) Was the outcome assessor blinded to } \\
\text { the intervention? }\end{array}$} & $\begin{array}{l}\text { Adequacy of blinding should be assessed for each primary outcome } \\
\text { separately. This item should be scored "yes" if the success of blinding } \\
\text { was tested among the outcome assessors and it was successful or: }\end{array}$ & \multirow[t]{6}{*}{$\begin{array}{l}\text { Yes/No/ } \\
\text { Unsure }\end{array}$} \\
\hline & & $\begin{array}{l}\text { - For patient-reported outcomes in which the patient is the outcome } \\
\text { assessor (eg, pain, disability): the blinding procedure is adequate for } \\
\text { outcome assessors if participant blinding is scored "yes" }\end{array}$ & \\
\hline & & $\begin{array}{l}\text { - For outcome criteria assessed during scheduled visit and that } \\
\text { supposes a contact between participants and outcome assessors (eg, } \\
\text { clinical examination): the blinding procedure is adequate if patients } \\
\text { are blinded, and the treatment or adverse effects of the treatment } \\
\text { cannot be noticed during clinical examination }\end{array}$ & \\
\hline & & $\begin{array}{l}\text { - For outcome criteria that do not suppose a contact with participants } \\
\text { (eg, radiography, magnetic resonance imaging): the blinding } \\
\text { procedure is adequate if the treatment or adverse effects of the } \\
\text { treatment cannot be noticed when assessing the main outcome }\end{array}$ & \\
\hline & & $\begin{array}{l}\text { - For outcome criteria that are clinical or therapeutic events that will } \\
\text { be determined by the interaction between patients and care } \\
\text { providers (eg, cointerventions, hospitalization length, treatment } \\
\text { failure), in which the care provider is the outcome assessor: the } \\
\text { blinding procedure is adequate for outcome assessors if item "4" } \\
\text { (caregivers) is scored "yes" }\end{array}$ & \\
\hline & & $\begin{array}{l}\text { - For outcome criteria that are assessed from data of the medical forms: } \\
\text { the blinding procedure is adequate if the treatment or adverse effects of } \\
\text { the treatment cannot be noticed on the extracted data }\end{array}$ & \\
\hline
\end{tabular}

(Continued) 
Table I (Continued).

\begin{tabular}{|c|c|c|c|}
\hline $\begin{array}{l}\text { Bias } \\
\text { Domain }\end{array}$ & \multicolumn{2}{|r|}{ Source of Bias } & $\begin{array}{l}\text { Possible } \\
\text { Answers }\end{array}$ \\
\hline Attrition & $\begin{array}{l}\text { (6) Was the drop-out rate described and } \\
\text { acceptable? }\end{array}$ & $\begin{array}{l}\text { The number of participants who were included in the study but did not } \\
\text { complete the observation period or were not included in the analysis } \\
\text { must be described and reasons given. If the percentage of withdrawals } \\
\text { and drop-outs does not exceed } 20 \% \text { for short-term follow-up and } 30 \% \\
\text { for long-term follow-up and does not lead to substantial bias a "yes" is } \\
\text { scored (N.B. these percentages are arbitrary, not supported by } \\
\text { literature). }\end{array}$ & $\begin{array}{l}\text { Yes/No/ } \\
\text { Unsure }\end{array}$ \\
\hline Attrition & $\begin{array}{l}\text { (7) Were all randomized participants } \\
\text { analyzed in the group to which they were } \\
\text { allocated? }\end{array}$ & $\begin{array}{l}\text { All randomized patients are reported/analyzed in the group they were } \\
\text { allocated to by randomization for the most important moments of } \\
\text { effect measurement (minus missing values) irrespective of } \\
\text { noncompliance and cointerventions. }\end{array}$ & $\begin{array}{l}\text { Yes/No/ } \\
\text { Unsure }\end{array}$ \\
\hline Reporting & $\begin{array}{l}\text { (8) Are reports of the study free of } \\
\text { suggestion of selective outcome reporting? }\end{array}$ & $\begin{array}{l}\text { All the results from all prespecified outcomes have been adequately } \\
\text { reported in the published report of the trial. This information is either } \\
\text { obtained by comparing the protocol and the report, or in the absence } \\
\text { of the protocol, assessing that the published report includes enough } \\
\text { information to make this judgment. }\end{array}$ & $\begin{array}{l}\text { Yes/No/ } \\
\text { Unsure }\end{array}$ \\
\hline Selection & $\begin{array}{l}\text { (9) Were the groups similar at baseline } \\
\text { regarding the most important prognostic } \\
\text { indicators? }\end{array}$ & $\begin{array}{l}\text { Groups have to be similar at baseline regarding demographic factors, } \\
\text { duration and severity of complaints, percentage of patients with } \\
\text { neurological symptoms, and value of main outcome measure(s). }\end{array}$ & $\begin{array}{l}\text { Yes/No/ } \\
\text { Unsure }\end{array}$ \\
\hline Performance & $\begin{array}{l}\text { (10) Were cointerventions avoided or } \\
\text { similar? }\end{array}$ & $\begin{array}{l}\text { If there were no cointerventions or they were similar between the } \\
\text { index and control groups. }\end{array}$ & $\begin{array}{l}\text { Yes/No/ } \\
\text { Unsure }\end{array}$ \\
\hline Performance & $\begin{array}{l}\text { (II) Was the compliance acceptable in all } \\
\text { groups? }\end{array}$ & $\begin{array}{l}\text { The reviewer determines if the compliance with the interventions is } \\
\text { acceptable, based on the reported intensity, duration, number and } \\
\text { frequency of sessions for both the index intervention and control } \\
\text { intervention(s). For example, physiotherapy treatment is usually } \\
\text { administered for several sessions; therefore it is necessary to assess } \\
\text { how many sessions each patient attended. For single-session } \\
\text { interventions (eg, surgery), this item is irrelevant. }\end{array}$ & $\begin{array}{l}\text { Yes/No/ } \\
\text { Unsure }\end{array}$ \\
\hline Detection & $\begin{array}{l}\text { (12) Was the timing of the outcome } \\
\text { assessment similar in all groups? }\end{array}$ & $\begin{array}{l}\text { Timing of outcome assessment should be identical for all intervention } \\
\text { groups and for all primary outcome measures. }\end{array}$ & $\begin{array}{l}\text { Yes/No/ } \\
\text { Unsure }\end{array}$ \\
\hline \multirow[t]{2}{*}{ Other } & \multirow{2}{*}{$\begin{array}{l}\text { (13) Are other sources of potential bias } \\
\text { unlikely? }\end{array}$} & Other types of biases. For example: & \multirow{2}{*}{$\begin{array}{l}\text { Yes/No/ } \\
\text { Unsure }\end{array}$} \\
\hline & & $\begin{array}{l}\text { - When the outcome measures were not valid. There should be } \\
\text { evidence from a previous or present scientific study that the primary } \\
\text { outcome can be considered valid in the context of the present. } \\
\text { - Industry-sponsored trials. The conflict of interest (COI) statement } \\
\text { should explicitly state that the researchers have had full possession } \\
\text { of the trial process from planning to reporting without funders with } \\
\text { potential COI having any possibility to interfere in the process. If, for } \\
\text { example, the statistical analyses have been done by a funder with a } \\
\text { potential COI, usually "unsure" is scored. }\end{array}$ & \\
\hline
\end{tabular}

Notes: Adapted and modified from: Furlan AD, Malmivaara A, Chou R, et al; Editorial Board of the Cochrane Back, Neck Group. 2015 Updated method guideline for systematic reviews in the Cochrane Back and Neck Group. Spine (Phila Pa 1976). 2015;40(21):1660-1673. With permission from the American Society of Interventional Pain Physicians. ${ }^{53}$ 
Table 2 Item Checklist for Assessment of Randomized Controlled Trials of IPM Techniques Utilizing IPM - QRB

\begin{tabular}{|c|c|c|}
\hline & & Scoring \\
\hline I. & TRIAL DESIGN AND GUIDANCE REPORTING & \\
\hline \multirow[t]{5}{*}{ I. } & CONSORT or SPIRIT & \\
\hline & Trial designed and reported without any guidance & 0 \\
\hline & Trial designed and reported utilizing minimum criteria other than CONSORT or SPIRIT criteria or trial was conducted prior to 2005 & I \\
\hline & $\begin{array}{l}\text { Trial implies it was based on CONSORT or SPIRIT without clear description with moderately significant criteria for randomized } \\
\text { trials or the trial was conducted before } 2005\end{array}$ & 2 \\
\hline & $\begin{array}{l}\text { Explicit use of CONSORT or SPIRIT with identification of criteria or trial conducted with high level reporting and criteria or } \\
\text { conducted before } 2005\end{array}$ & 3 \\
\hline II. & DESIGN FACTORS & \\
\hline \multirow[t]{4}{*}{2.} & Type and Design of Trial & \\
\hline & Poorly designed control group (quasi selection, convenient sampling) & 0 \\
\hline & Proper active-control or sham procedure with injection of active agent & 2 \\
\hline & Proper placebo control (no active solutions into active structures) & 3 \\
\hline \multirow[t]{4}{*}{3.} & Setting/Physician & \\
\hline & General setting with no specialty affiliation and general physician & 0 \\
\hline & Specialty of anesthesia/PMR/neurology/radiology/ortho, etc. & I \\
\hline & Interventional pain management with interventional pain management physician & 2 \\
\hline \multirow[t]{5}{*}{4.} & Imaging & \\
\hline & Blind procedures & 0 \\
\hline & Ultrasound & 1 \\
\hline & CT & 2 \\
\hline & Fluoro & 3 \\
\hline \multirow[t]{5}{*}{5.} & Sample Size & \\
\hline & Less than 50 participants in the study without appropriate sample size determination & 0 \\
\hline & Sample size calculation with less than 25 patients in each group & I \\
\hline & Appropriate sample size calculation with at least 25 patients in each group & 2 \\
\hline & Appropriate sample size calculation with 50 patients in each group & 3 \\
\hline \multirow[t]{3}{*}{6.} & Statistical Methodology & \\
\hline & None or inappropriate & 0 \\
\hline & Appropriate & I \\
\hline III. & PATIENT FACTORS & \\
\hline 7. & Inclusiveness of Population & \\
\hline \multirow[t]{4}{*}{ 7a. } & For epidural procedures: & \\
\hline & Poorly identified mixed population & 0 \\
\hline & Clearly identified mixed population & 1 \\
\hline & $\begin{array}{l}\text { Disorders specific trials (ie, well-defined spinal stenosis and disc herniation, disorder specific, disc herniation or spinal stenosis or } \\
\text { post surgery syndrome) }\end{array}$ & 2 \\
\hline \multirow[t]{4}{*}{ 7b. } & For facet or sacroiliac joint interventions: & \\
\hline & No diagnostic blocks & 0 \\
\hline & Selection with single diagnostic blocks & I \\
\hline & Selection with placebo or dual diagnostic blocks & 2 \\
\hline \multirow[t]{4}{*}{8.} & Duration of Pain & \\
\hline & $<3$ months & 0 \\
\hline & $3-6$ months & I \\
\hline & $>6$ months & 2 \\
\hline
\end{tabular}

(Continued) 
Table 2 (Continued).

\begin{tabular}{|c|c|c|}
\hline & & Scoring \\
\hline 9. & $\begin{array}{l}\text { Previous Treatments } \\
\text { Conservative management including drug therapy, exercise therapy, physical therapy, etc. } \\
\text { Were not utilized } \\
\text { Were utilized sporadically in some patients } \\
\text { Were utilized in all patients }\end{array}$ & $\begin{array}{l}0 \\
1 \\
2\end{array}$ \\
\hline 10. & $\begin{array}{l}\text { Duration of Follow-up with Appropriate Interventions } \\
\text { Less than } 3 \text { months or } 12 \text { weeks for epidural or facet joint procedures, etc. and } 6 \text { months for intradiscal procedures and } \\
\text { implantables } \\
3-6 \text { months for epidural or facet joint procedures, etc., or I year for intradiscal procedures or implantables } \\
6-17 \text { months for epidurals or facet joint procedures, etc., and } 2 \text { years or longer for discal procedures and implantables } \\
18 \text { months or longer for epidurals and facet joint procedures, etc., or } 5 \text { years or longer for discal procedures and implantables }\end{array}$ & $\begin{array}{l}1 \\
2 \\
3\end{array}$ \\
\hline IV. & OUTCOMES & \\
\hline II. & $\begin{array}{l}\text { Outcomes Assessment Criteria for Significant Improvement } \\
\text { No descriptions of outcomes OR }<20 \% \text { change in pain rating or functional status } \\
\text { Pain rating with a decrease of } 2 \text { or more points or more than } 20 \% \text { reduction OR functional status improvement of more than } 20 \% \\
\text { Pain rating with decrease of } \geq 2 \text { points AND } \geq 20 \% \text { change or functional status improvement of } \geq 20 \% \\
\text { Pain rating with a decrease of } 3 \text { or more points or more than } 50 \% \text { reduction OR functional status improvement with a } 50 \% \text { or } 40 \% \\
\text { reduction in disability score } \\
\text { Significant improvement with pain and function } \geq 50 \% \text { or } 3 \text { points and } 40 \% \text { reduction in disability scores }\end{array}$ & $\begin{array}{l}0 \\
1 \\
2 \\
2\end{array}$ \\
\hline 12. & $\begin{array}{l}\text { Analysis of all Randomized Participants in the Groups } \\
\text { Not performed } \\
\text { Performed without intent-to-treat analysis without inclusion of all randomized participants } \\
\text { All participants included with or without intent-to-treat analysis }\end{array}$ & $\begin{array}{l}0 \\
1 \\
2\end{array}$ \\
\hline 13. & $\begin{array}{l}\text { Description of Drop-Out Rate } \\
\text { No description of dropouts, despite reporting of incomplete data or } \geq 20 \% \text { withdrawal } \\
\text { Less than } 20 \% \text { withdrawal in I year in any group } \\
\text { Less than } 30 \% \text { withdrawal at } 2 \text { years in any group }\end{array}$ & $\begin{array}{l}0 \\
1 \\
2\end{array}$ \\
\hline 14. & $\begin{array}{l}\text { Similarity of Groups at Baseline for Important Prognostic Indicators } \\
\text { Groups dissimilar with significant influence on outcomes with or without appropriate randomization and allocation } \\
\text { Groups dissimilar without influence on outcomes despite appropriate randomization and allocation } \\
\text { Groups similar with appropriate randomization and allocation }\end{array}$ & $\begin{array}{l}0 \\
1 \\
2\end{array}$ \\
\hline 15. & $\begin{array}{l}\text { Role of Co-Interventions } \\
\text { Co-interventions were provided but were not similar in the majority of participants } \\
\text { No co-interventions or similar co-interventions were provided in the majority of the participants } \\
\text { Randomization }\end{array}$ & $\begin{array}{l}0 \\
1\end{array}$ \\
\hline 16. & $\begin{array}{l}\text { Method of Randomization } \\
\text { Quasi randomized or poorly randomized or not described } \\
\text { Adequate randomization (coin toss, drawing of balls of different colors, drawing of ballots) } \\
\text { High quality randomization (Computer generated random sequence, pre-ordered sealed envelopes, sequentially ordered vials, } \\
\text { telephone call, pre-ordered list of treatment assignments, etc) }\end{array}$ & $\begin{array}{l}0 \\
1 \\
2\end{array}$ \\
\hline VI. & ALLOCATION CONCEALMENT & \\
\hline 17. & $\begin{array}{l}\text { Concealed Treatment Allocation } \\
\text { Poor concealment of allocation (open enrollment) or inadequate description of concealment } \\
\text { Concealment of allocation with borderline or good description of the process with probability of failure of concealment } \\
\text { High-quality concealment with strict controls (independent assignment without influence on the assignment sequence) }\end{array}$ & $\begin{array}{l}0 \\
1\end{array}$ \\
\hline
\end{tabular}


Table 2 (Continued).

\begin{tabular}{|c|c|c|}
\hline & & Scoring \\
\hline VII. & BLINDING & \\
\hline \multirow[t]{3}{*}{18.} & Patient Blinding & \\
\hline & Patients not blinded & 0 \\
\hline & Patients blinded adequately & I \\
\hline \multirow[t]{3}{*}{19.} & Care Provider Blinding & \\
\hline & Care provider not blinded & 0 \\
\hline & Care provider blinded adequately & 1 \\
\hline \multirow[t]{3}{*}{20.} & Outcome Assessor Blinding & \\
\hline & Outcome assessor not blinded or was able to identify the groups & 0 \\
\hline & $\begin{array}{l}\text { Performed by a blinded independent assessor with inability to identify the assignment-based provider intervention (ie, subcutaneous } \\
\text { injection, intramuscular distant injection, difference in preparation or equipment use, numbness and weakness, etc.) }\end{array}$ & 1 \\
\hline VIII. & CONFLICTS OF INTEREST & \\
\hline \multirow[t]{7}{*}{21.} & Funding and Sponsorship & \\
\hline & Trial included industry employees & -3 \\
\hline & Industry employees involved; high levels of funding with remunerations by industry or an organization funded with conflicts & -3 \\
\hline & Industry or organizational funding with reimbursement of expenses with some involvement & 0 \\
\hline & Industry or organization funding of expenses without involvement & I \\
\hline & Funding by internal resources only with supporting entity unrelated to industry & 2 \\
\hline & Governmental funding without conflict such as $\mathrm{NIH}, \mathrm{NHS}$, AHRQ & 3 \\
\hline \multirow[t]{8}{*}{22.} & Conflicts of Interest & \\
\hline & None disclosed with potential implied conflict & 0 \\
\hline & Marginally disclosed with potential conflict & I \\
\hline & Well disclosed with minor conflicts & 2 \\
\hline & Well disclosed with no conflicts & 3 \\
\hline & Hidden conflicts with poor disclosure & -1 \\
\hline & Misleading disclosure with conflicts & -2 \\
\hline & Major impact related to conflicts & -3 \\
\hline \multicolumn{2}{|c|}{ TOTAL } & 48 \\
\hline
\end{tabular}

Notes: Source: Manchikanti L, Hirsch JA, Cohen SP, et al. Assessment of methodologic quality of randomized trials of interventional techniques: Development of an interventional pain management specific instrument. Pain Physician. 20I4;I7(3):E263-E290. ${ }^{54}$

\section{Outcome Measures}

An outcome is considered clinically significant if a reduction of 3 points on Visual Analog Scale (VAS) or Numeric Rating Scale (NRS), or at least $50 \%$ reduction in pain and improvement in the functional status. A positive study is said to be clinically significant and effective indicating that the primary outcome should be statistically significant at a $P$-value $\leq 0.05$.

\section{Analysis of Evidence}

The evidence was analyzed utilizing qualitative and quantitative evidence synthesis. Quantitative evidence synthesis was performed utilizing conventional meta-analysis and a single-arm metaanalysis.

\section{Qualitative Analysis}

The qualitative analysis of the evidence was performed based on best-evidence synthesis, modified and collated using multiple criteria, including the Cochrane Review criteria and United States Preventive Services Task Force (USPSTF) criteria as illustrated in Table $3 .^{55}$ The analysis was conducted using five levels of evidence ranging from strong to opinion- or consensus-based. The results of best evidence as per grading were utilized. At least two of the review authors independently, in a standardized manner, analyzed the evidence. Any disagreements between reviewers were resolved by a third author and consensus was attained. If there were any conflicts of interest (eg, authorship), the reviewers of interest were recused from assessment and analysis. 
Table 3 Qualitative Modified Approach to Grading of Evidence of Therapeutic Effectiveness Studies

\begin{tabular}{|l|l|l|}
\hline Level I & Strong & Evidence obtained from multiple relevant high-quality randomized controlled trials \\
\hline Level II & Moderate & $\begin{array}{l}\text { Evidence obtained from at least one relevant high-quality randomized controlled trial or multiple relevant } \\
\text { moderate or low-quality randomized controlled trials }\end{array}$ \\
\hline Level III & Fair & $\begin{array}{l}\text { Evidence obtained from at least one relevant moderate or low-quality randomized trial or Evidence obtained } \\
\text { from at least one relevant high-quality non-randomized trial or observational study with multiple moderate or } \\
\text { low-quality observational studies }\end{array}$ \\
\hline Level IV & Limited & Evidence obtained from multiple moderate or low-quality relevant observational studies \\
\hline Level V & $\begin{array}{l}\text { Consensus } \\
\text { based }\end{array}$ & Opinion or consensus of large group of clinicians and/or scientists \\
\hline
\end{tabular}

Notes: Modified from: Manchikanti L, Falco FJE, Benyamin RM, Kaye AD, Boswell MV, Hirsch JA. A modified approach to grading of evidence. Pain Physician. 20 I4; I7(3):E3 I9E325. ${ }^{55}$.

\section{Meta-Analysis}

For dual-arm meta-analysis, Review Manager software (Rev Man 5.3) was used (The Nordic Cochrane Centre, The Cochrane Collaboration, Copenhagen, Denmark, 2008).

For single-arm meta-analysis, software Comprehensive Meta-analysis version 3.0 was used (Biostat Inc., Englewood, NJ).

For pain and improvement of function data, the studies were reported as the standardized mean differences (SMD) with $95 \%$ confidence intervals (CI).

Data were plotted by using forest plots to evaluate treatment effects. Heterogeneity was interpreted through $\mathrm{I}^{2}$ statistics.

\section{Results}

The flow diagram illustrates the search results and the final number of studies that were considered for inclusion (Figure 1).

The full manuscript was reviewed for 89 studies, out of which $15 \mathrm{RCTs}^{56-70}$ were selected and 12 of them met the inclusion criteria to include in this systematic review. Three trials were excluded. ${ }^{57,58,70}$ Civelek et $\mathrm{al}^{57}$ was excluded due to lack of diagnostic blocks prior to providing radiofrequency denervation procedure. Cohen et $\mathrm{al}^{58}$ and van Tilburg et $\mathrm{al}^{70}$ was excluded due to short-term assessment of 3 months. Of the remaining 12 trials, 7 of them were active control trials, ${ }^{56,59,60,62-64,66}$ and the remaining 5 were placebo or sham control. ${ }^{61,65,67-69}$

\section{Methodological Quality Assessment}

The results of methodological quality assessment of the RCTs meeting the inclusion criteria carried out using
Cochrane review criteria and IPM-QRB criteria are illustrated in Tables 4 and 5.

Utilizing the Cochrane quality assessment and the previously established score ranges in the methods section of this study, 10 trials ${ }^{56,59,60,62-65,67-69}$ scored between 9 and 13 , thus meeting our criteria of high-quality studies, while 2 trials $^{61,66}$ scored between 5 and 8 , thus said to be studies of moderate quality.

Based on the IPM-QRB criteria for randomized trials, 8 trials $^{56,59,60,62-64,68,69}$ scored between 32 and 48, hence they are of high quality, while 4 trials ${ }^{61,65-67}$ scored between 16 and 31, thus are considered as moderate quality trials. Thus, only 8 trials met the criteria for highquality with both instruments. ${ }^{56,59,60,62-64,68,69}$ This indicates the importance of IPM specific instruments in methodologic quality assessments.

\section{Study Characteristics}

Table 6 shows the study characteristics of all the included randomized trials.

\section{Analysis of Evidence Qualitative Analysis}

Table 7 shows the effectiveness of radiofrequency neurotomy. The included trials studied a total of 1049 patients, with 461 patients undergoing conventional radiofrequency neurotomy. Among these, in 10 positive trials, the total number of patients included were 717 with 296 undergoing conventional radiofrequency neurotomy. Among the two negative trials, ${ }^{61,68}$ a total of 332 patients were included with 165 undergoing radiofrequency neurotomy. Juch et $\mathrm{al}^{61}$ with low methodological quality and high risk of bias, included 125 of 251 patients with conventional radiofrequency 


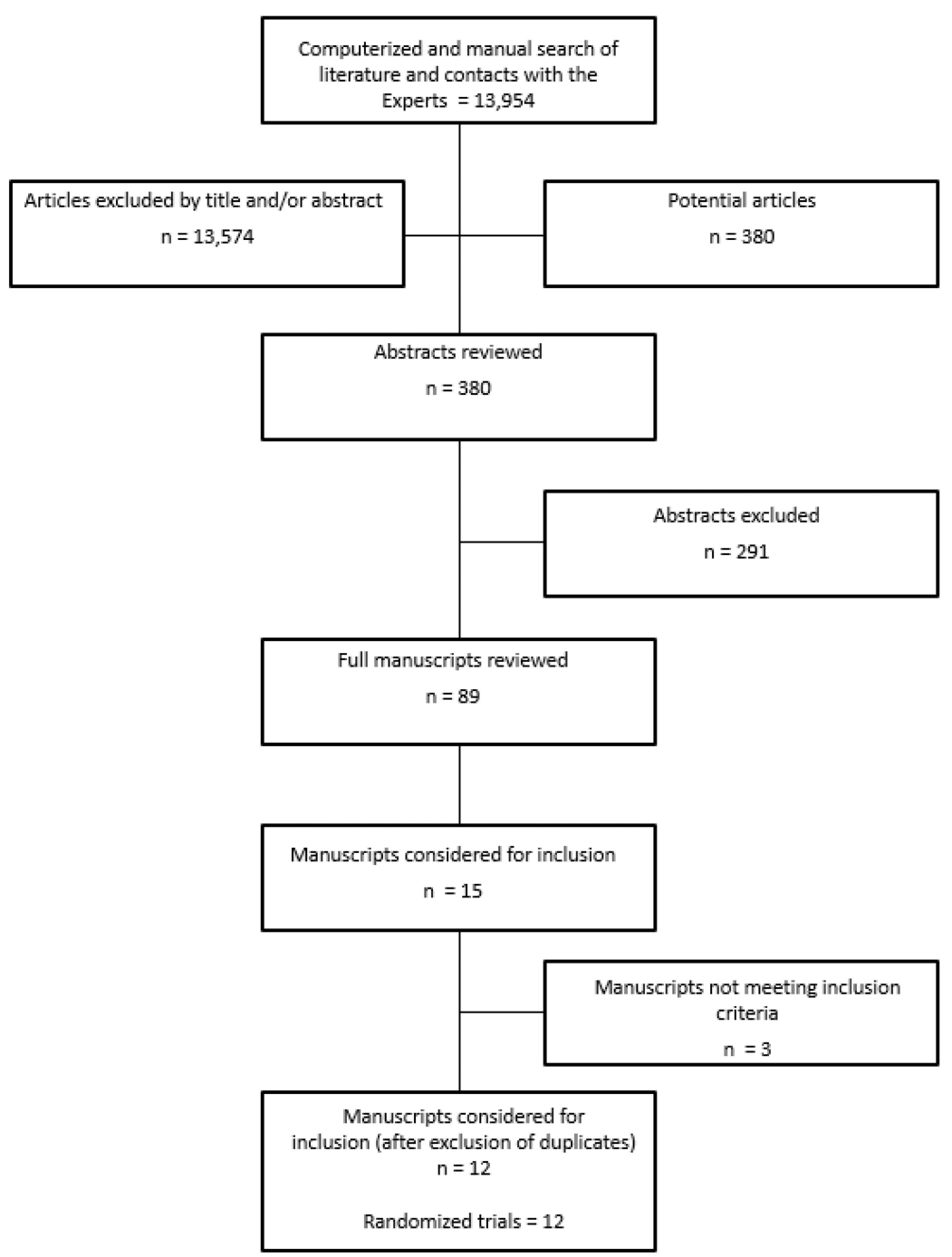

Figure I Flow diagram illustrating the results of literature search conducted to evaluate lumbar radiofrequency thermoneurolysis.

neurotomy. Whereas, the second study by van Wijk et $\mathrm{al}^{68}$ included 81 patients with 40 patients undergoing conventional radiofrequency. Thus, a total of 165 patients were studied with conventional radiofrequency neurotomy with lack of improvement or considered negative; however, only van Wijk et $\mathrm{al}^{68}$ was sham controlled. Consequently, based on 12 studies, a total of 1049 patients were included with 461 undergoing radiofrequency neurotomy, with 296 of 717 showing positive results and 165 of 332 showing negative results. Among positive trials, the number of patients in each study varied from 16 to 45 . Among the four sham controlled trials, ${ }^{64,65,68,69}$ one study was negative on both short-term and long-term follow-up, ${ }^{68}$ whereas two studies were positive, ${ }^{64,69}$ both for short and long term and one study was positive for only short-term. ${ }^{65}$
Overall, based on the qualitative analysis, the level of evidence of efficacy is Level II with moderate evidence.

\section{Quantitative Analysis}

Quantitative analysis was performed utilizing conventional dual-arm meta-analysis and single-arm meta-analysis. The data from all the RCTs providing appropriate criteria were included withsix trials qualifying for dualarm meta-analysis in one of the categories; whereas, for single-arm meta-analysis 10 RCTs met criteria for inclusion.

\section{Conventional Dual-Arm Meta-Analysis}

Of the five placebo or sham controlled studies, ${ }^{61,65,67-69}$ two studies were not included due to lack of availability of 
Table 4 Methodological Quality Assessment of Randomized Trials of Lumbar Facet Joint Radiofrequency Thermoneurolysis Utilizing Cochrane Review Criteria ${ }^{53}$

\begin{tabular}{|c|c|c|c|c|c|c|c|}
\hline & Juch et $\mathrm{al}^{61}$ & Nath et al ${ }^{65}$ & $\begin{array}{l}\text { Tekin } \\
\text { et } \mathrm{al}^{67}\end{array}$ & $\begin{array}{l}\text { van Wijk } \\
\text { et } \mathrm{al}^{68}\end{array}$ & $\begin{array}{l}\text { van Kleef } \\
\text { et } \mathrm{al}^{69}\end{array}$ & $\begin{array}{l}\text { Çetin \& } \\
\text { Yektaș }^{56}\end{array}$ & $\begin{array}{l}\text { Lakemeier } \\
\text { et } \text { al }^{59}\end{array}$ \\
\hline Randomization adequate & Y & $Y$ & $Y$ & $Y$ & $Y$ & $\mathrm{Y}$ & $Y$ \\
\hline Concealed treatment allocation & $\mathrm{N}$ & $Y$ & $Y$ & $Y$ & $Y$ & $\mathrm{Y}$ & $Y$ \\
\hline Patient blinded & $\mathrm{N}$ & Y & $Y$ & Y & Y & $Y$ & Y \\
\hline Care provider blinded & $\mathrm{N}$ & Y & Y & $Y$ & Y & $\mathrm{N}$ & $\mathrm{N}$ \\
\hline Outcome assessor blinded & $\mathrm{N}$ & $Y$ & $Y$ & $Y$ & $\mathrm{Y}$ & $Y$ & $\mathrm{~N}$ \\
\hline Drop-out rate described & $\mathrm{N}$ & $\mathrm{Y}$ & Y & Y & Y & Y & $Y$ \\
\hline $\begin{array}{l}\text { All randomized participants analyzed in the } \\
\text { group }\end{array}$ & $\mathrm{N}$ & Y & Y & Y & Y & $Y$ & $Y$ \\
\hline $\begin{array}{l}\text { Reports of the study free of suggestion of } \\
\text { selective outcome reporting }\end{array}$ & $\mathrm{N}$ & Y & Y & Y & Y & Y & Y \\
\hline $\begin{array}{l}\text { Groups similar at baseline regarding most } \\
\text { important prognostic indicators }\end{array}$ & Y & Y & $Y$ & Y & $Y$ & Y & Y \\
\hline Co-intervention avoided or similar in all groups & Y & Y & Y & Y & Y & Y & Y \\
\hline Compliance acceptable in all groups & Y & Y & Y & Y & Y & Y & $\mathrm{N}$ \\
\hline $\begin{array}{l}\text { Time of outcome assessment in all groups } \\
\text { similar }\end{array}$ & Y & Y & Y & Y & Y & Y & Y \\
\hline Are other sources of potential bias not likely & Y & Y & $U$ & Y & Y & Y & $U$ \\
\hline \multirow[t]{2}{*}{ SCORE } & $6 / 13$ & $13 / 13$ & $12 / 13$ & $13 / 13$ & $13 / 13$ & $12 / 13$ & $9 / 13$ \\
\hline & 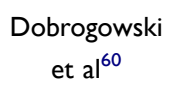 & $\begin{array}{l}\text { McCormick } \\
\text { et al }{ }^{62}\end{array}$ & $\begin{array}{l}\text { Moon } \\
\text { et } \mathrm{al}^{63}\end{array}$ & $\begin{array}{l}\text { Moussa \& } \\
\text { Khedr }^{64}\end{array}$ & $\begin{array}{l}\text { Song } \\
\text { et } \mathrm{al}^{66}\end{array}$ & & \\
\hline Randomization adequate & Y & Y & Y & Y & $U$ & & \\
\hline Concealed treatment allocation & $U$ & Y & Y & Y & $U$ & & \\
\hline Patient blinded & Y & Y & Y & Y & $\mathrm{N}$ & & \\
\hline Care provider blinded & Y & $\mathrm{N}$ & Y & $\mathrm{N}$ & $\mathrm{N}$ & & \\
\hline Outcome assessor blinded & $U$ & Y & Y & $\mathrm{Y}$ & Y & & \\
\hline Drop-out rate described & Y & Y & Y & $\mathrm{Y}$ & $\mathrm{N}$ & & \\
\hline $\begin{array}{l}\text { All randomized participants analyzed in the } \\
\text { group }\end{array}$ & Y & Y & $\mathrm{N}$ & 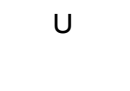 & $U$ & & \\
\hline $\begin{array}{l}\text { Reports of the study free of suggestion of } \\
\text { selective outcome reporting }\end{array}$ & Y & Y & Y & Y & Y & & \\
\hline $\begin{array}{l}\text { Groups similar at baseline regarding most } \\
\text { important prognostic indicators }\end{array}$ & Y & Y & Y & Y & Y & & \\
\hline Co-intervention avoided or similar in all groups & Y & Y & Y & Y & $\mathrm{N}$ & & \\
\hline Compliance acceptable in all groups & Y & Y & $\mathrm{N}$ & $U$ & $\mathrm{Y}$ & & \\
\hline
\end{tabular}


Table 4 (Continued).

\begin{tabular}{|l|c|c|c|c|c|c|}
\hline $\begin{array}{l}\text { Time of outcome assessment in all groups } \\
\text { similar }\end{array}$ & $Y$ & $Y$ & $N$ & $Y$ & $Y$ & \\
\hline Are other sources of potential bias not likely & $U$ & $U$ & $U$ & $Y$ & $Y$ & \\
\hline SCORE & $10 / 13$ & $11 / 13$ & $9 / 13$ & $10 / 13$ & $6 / 13$ & \\
\hline
\end{tabular}

Abbreviations: Y, yes; $\mathrm{N}$, no; $\mathrm{U}$, unclear.

appropriate data. Van Wijk et $\mathrm{al}^{68}$ provided only data at 3month follow-up, whereas 6- and 12-month follow-up data were not available. van Kleef et $\mathrm{al}^{69}$ had data available only at 8-week point time with no data to be included in meta-analysis at 6 and 12 months of follow-up. Consequently, a comparative cumulative analysis of data from three RCTs that compared lumbar radiofrequency neurotomy using conventional radiofrequency ablation (CRFA) with sham procedure as the control group was performed as shown in Figure 2.

Figure 2A shows short-term follow-up (6 months or less) data with inclusion of three trials. ${ }^{64,65,67}$ The cumulative analysis showed that radiofrequency neurotomy with CRFA reduced pain scores by 1.98 (with a $95 \%$ confidence interval between -0.5 and 4.47) compared to a sham procedure. However, it was not statistically significant with a $P$-value of 0.12 .

For 12-month data, only two studies were available, which included Tekin et $\mathrm{al}^{67}$ and Juch et $\mathrm{al}^{61}$. Out of the five trials, ${ }^{61,65,67-69}$ only two trials ${ }^{61,67}$ were available with data to be included as shown in Figure 2B.

Overall, there were four sham-controlled trials described as placebo-controlled. ${ }^{64,65,68,69}$ Among these, a single study ${ }^{68}$ showed negative results for short- and long-term improvement. One study presented only short-term results with improvement at 6 months (65). Two studies showed short-term and longterm positive results. ${ }^{64,69}$ Thus, three of the four placebo-controlled trials showed positive results for short term and two of the four showed positive results for short and long term.

The results in this analysis were favoring CRFA at 12 months.

Conventional dual-arm analysis was also performed at 6 and 12 months for active control trials. Overall, six studies were included of the seven active-controlled trials available (Figure 3).
The analysis showed the results favoring CRFA at 6 months; however, the results were favoring the active control group at 12 months.

Functional status using Oswestry Disability Index (ODI) scores was reported in only two out of thefive 5 trials $^{61,67}$ at 6-month follow-up point as shown in Figure 4. At 12 months, functional status was assessed utilizing ODI in only in two studies. ${ }^{61,67}$

Outcomes results of sham-controlled trials and activecontrolled trials have been described in qualitative analysis.

\section{Single-Arm Meta-Analysis}

A single-arm cumulative analysis of the data from 10 RCTs, in which at least one arm of the study patients underwent radiofrequency neurotomy. The cumulative analysis was conducted between the initial and final pain VAS scores at 6 months follow-up in the CFRA arm of the studies.

In the single-arm cumulative analysis as shown in Figure 5A, CRFA reduced pain VAS score by 3.43 (with a $95 \%$ confidence interval between 2.66 and 4.19 ) at the end of 6 months follow-up. It was also statistically significant with a $P$-value of $<0.00001$.

Similarly, a single-arm cumulative analysis was done at 12 months follow-up, for which only five RCTs had the required data at 12 months (Figure 5B). The single-arm cumulative analysis showed that CRFA reduced pain VAS score by 3.68 (with a 95\% confidence interval between 2.34 and 5.02) at the end of the 12-month follow-up. It was also statistically significant at a $P$-value of $<0.00001$.

Single-arm analysis was also performed on functional status with ODI scores at 6 and 12 months. Only two studies met inclusion criteria, both at 6 and 12 months. As shown in Figure 6, the data showed significant improvement in functional status at 6 and 12 months in CRFA group. 


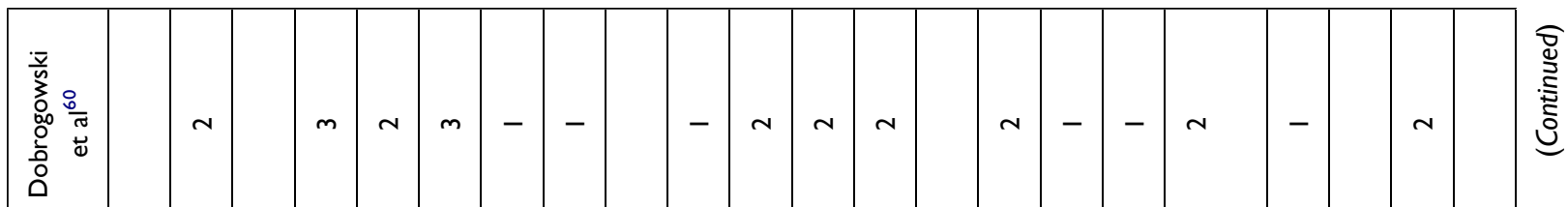

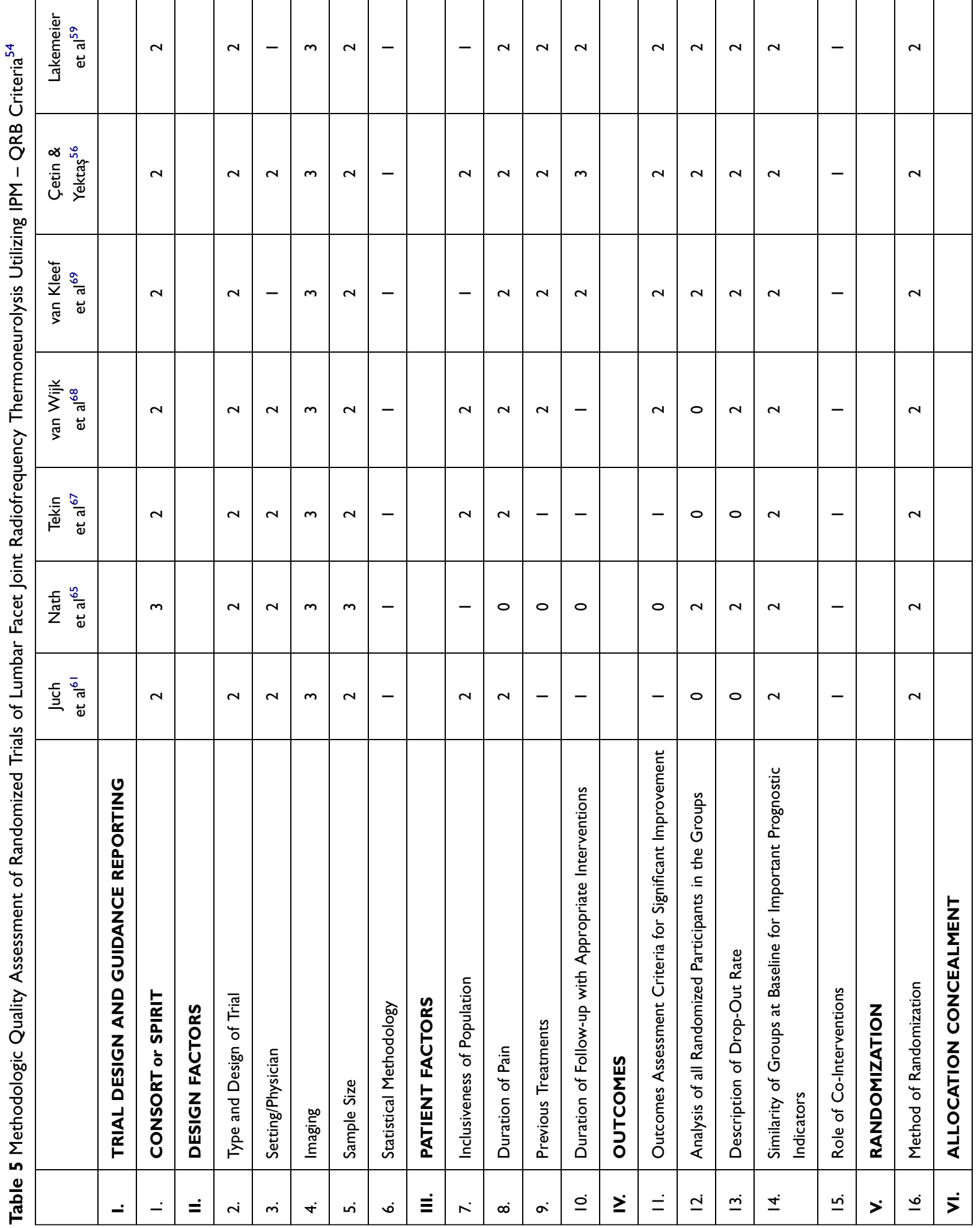




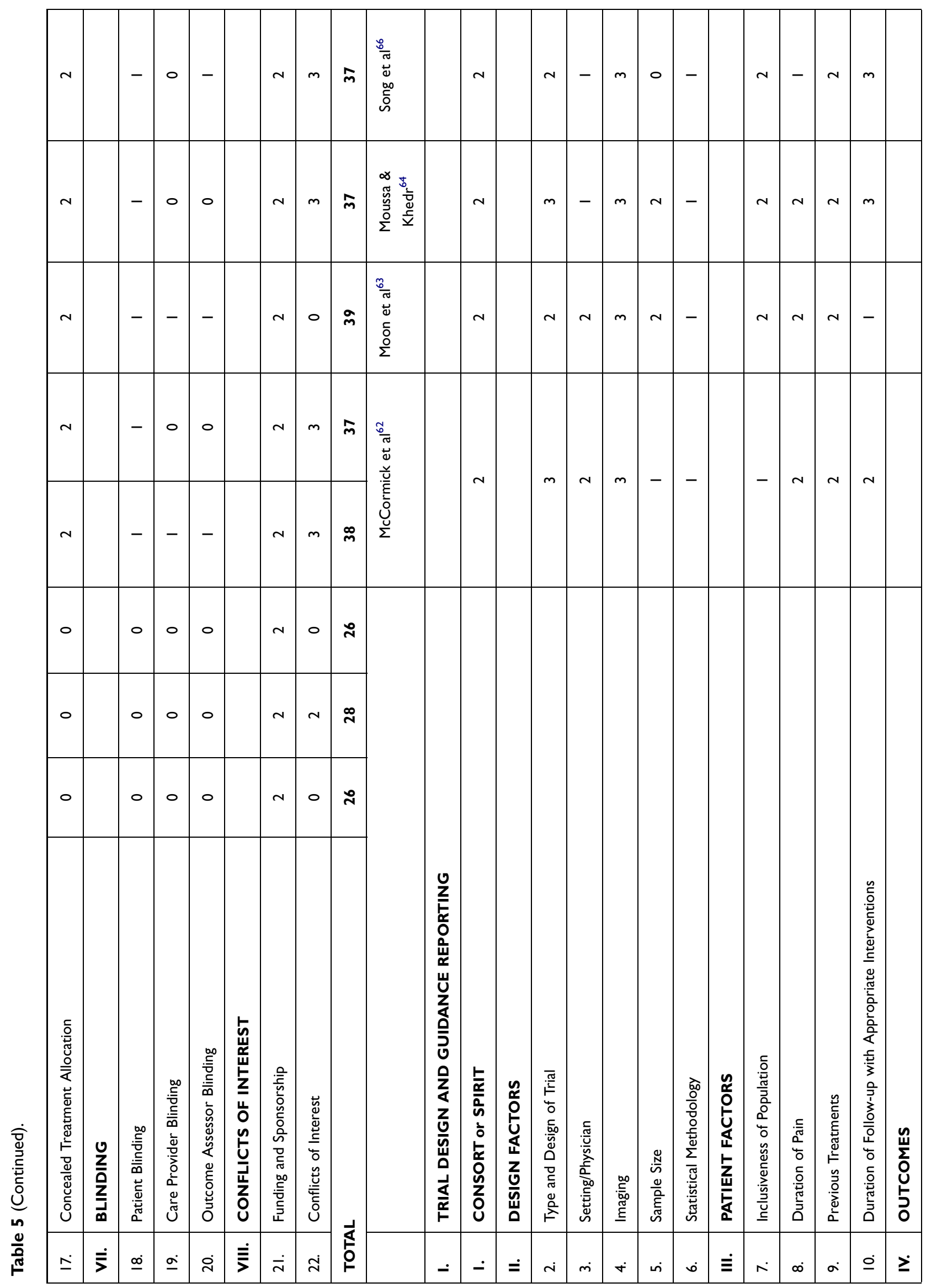




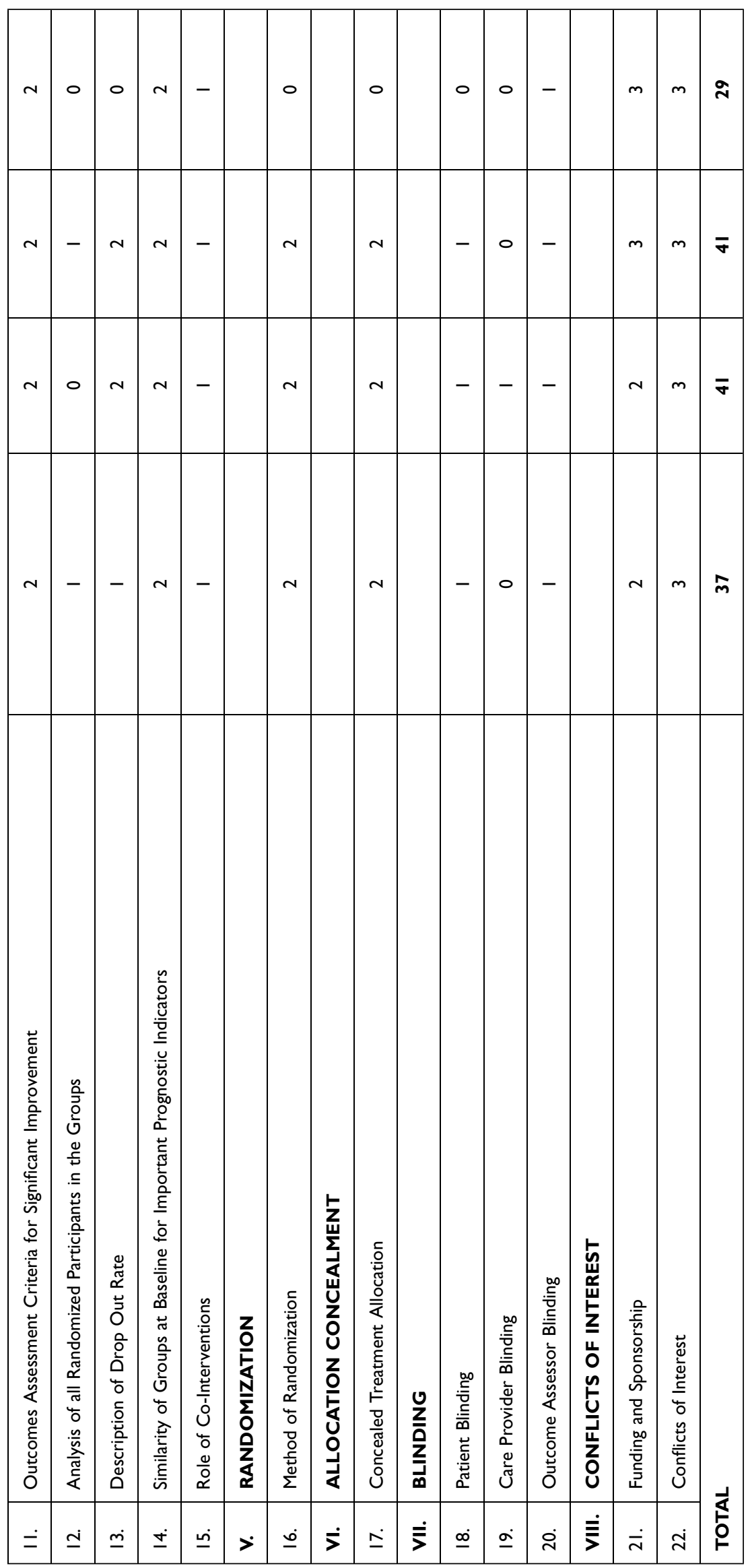




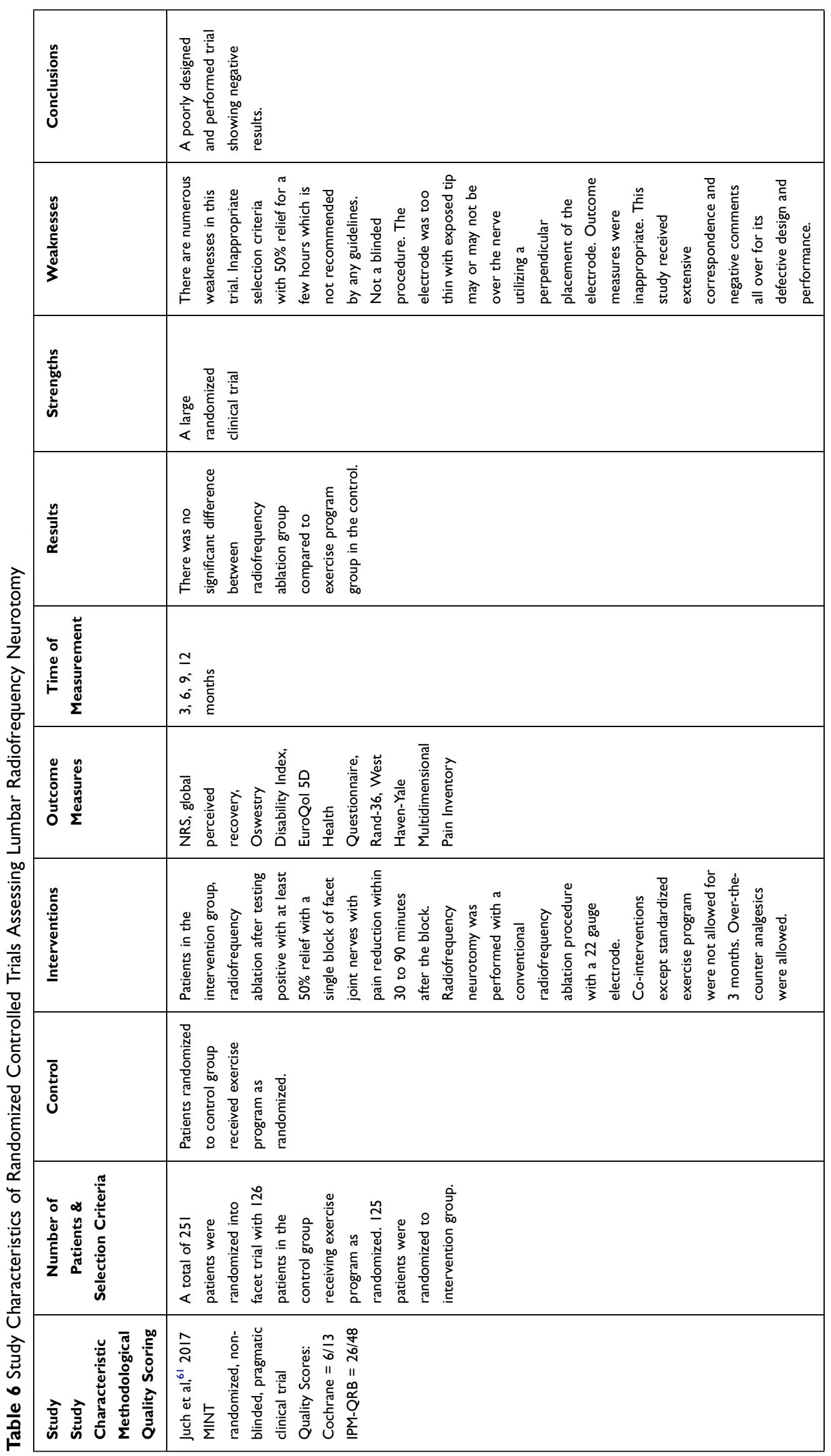




\begin{tabular}{|c|c|}
\hline 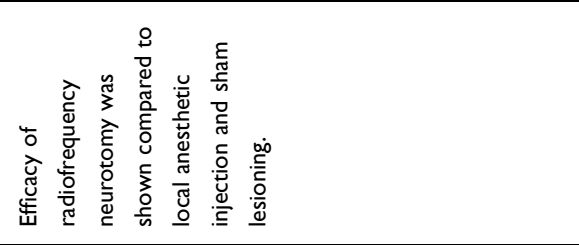 & 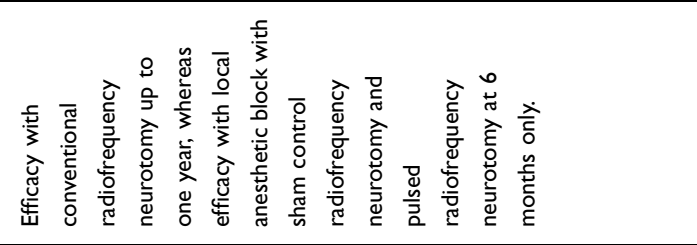 \\
\hline 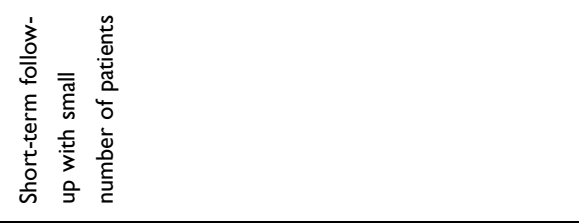 & 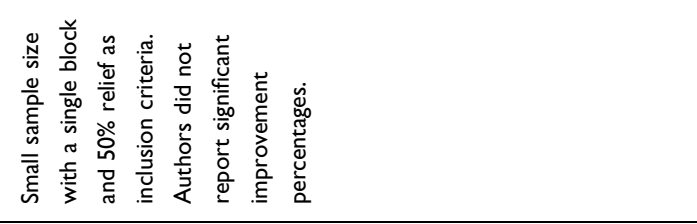 \\
\hline 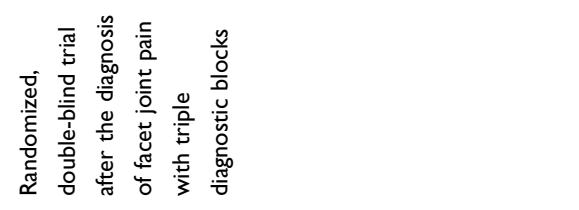 & 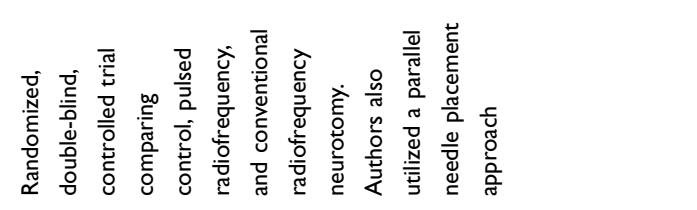 \\
\hline 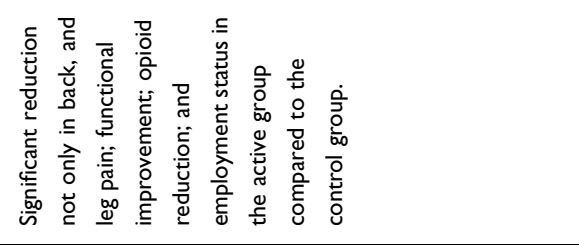 & 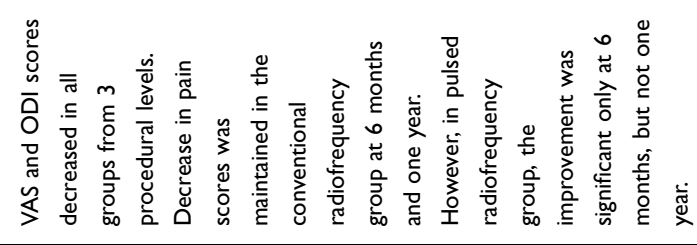 \\
\hline & 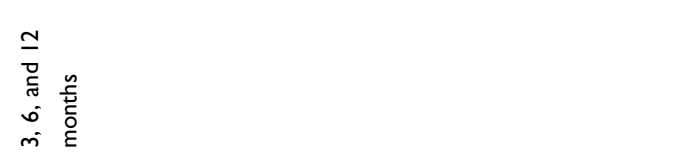 \\
\hline 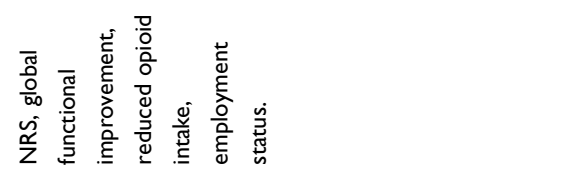 & 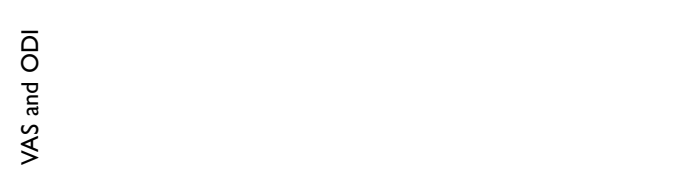 \\
\hline 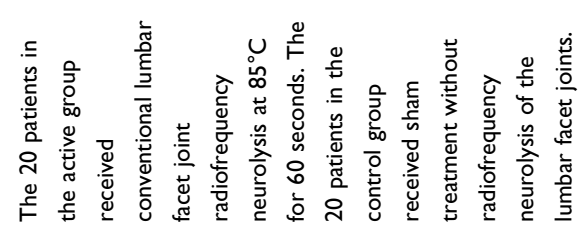 & 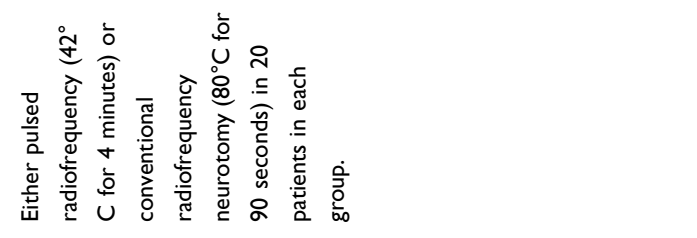 \\
\hline 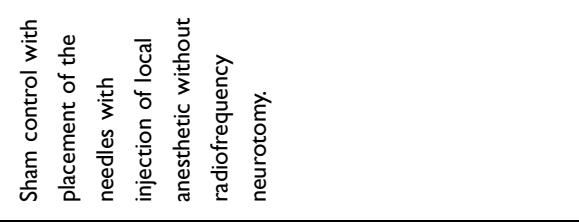 & 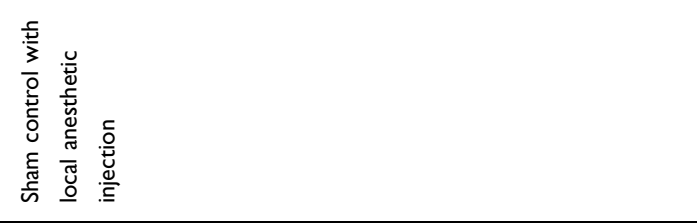 \\
\hline 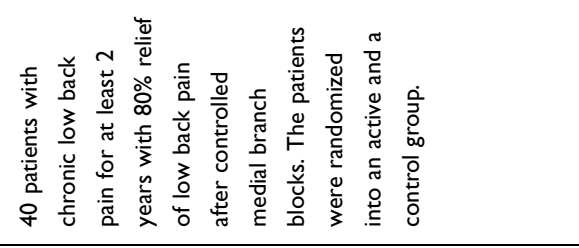 & 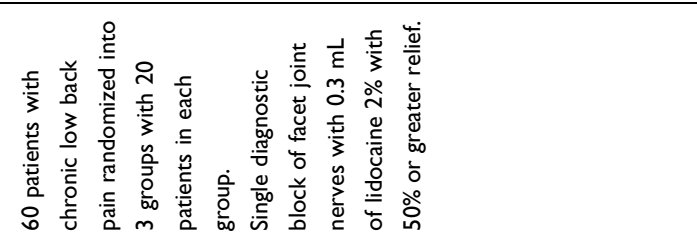 \\
\hline 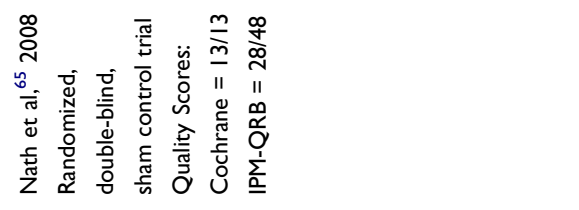 & 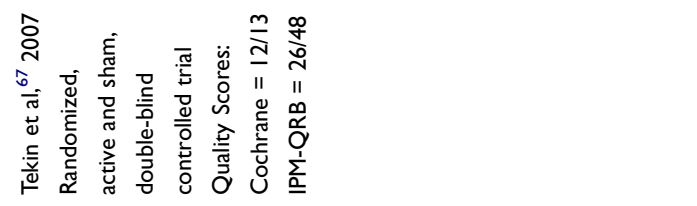 \\
\hline
\end{tabular}




\begin{tabular}{|c|c|c|}
\hline 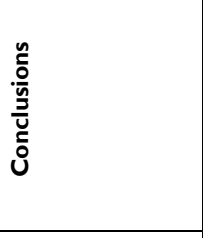 & 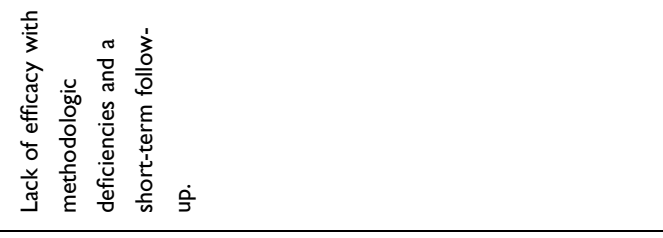 & 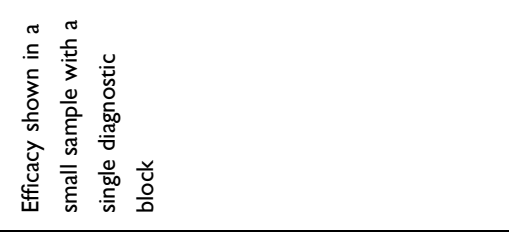 \\
\hline 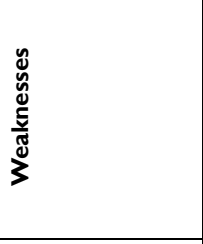 & 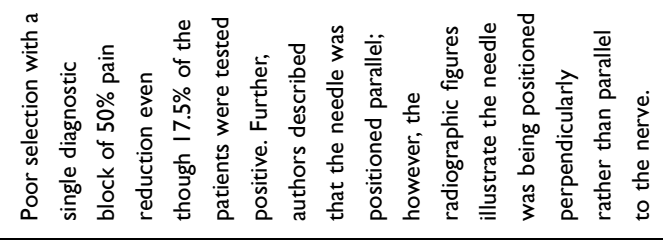 & 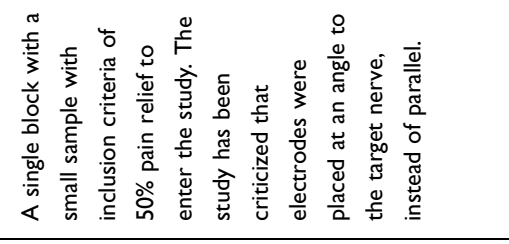 \\
\hline & 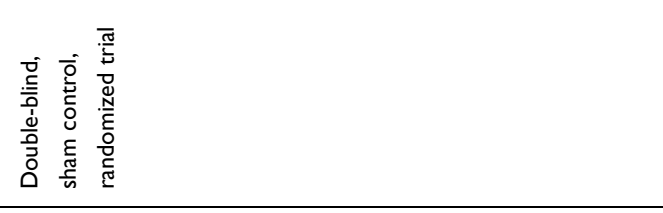 & 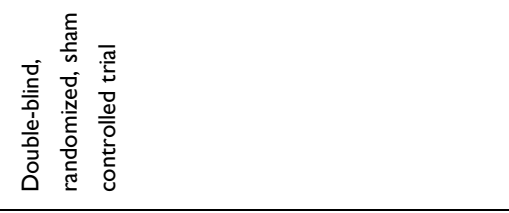 \\
\hline 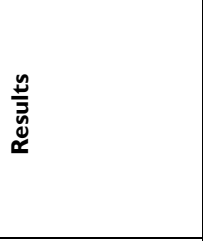 & 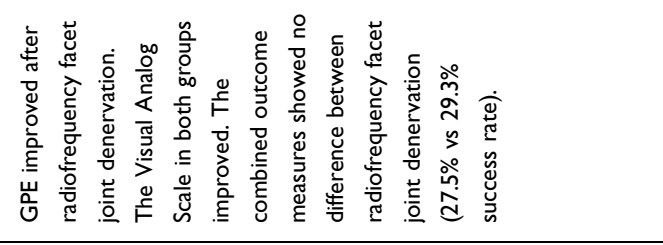 & 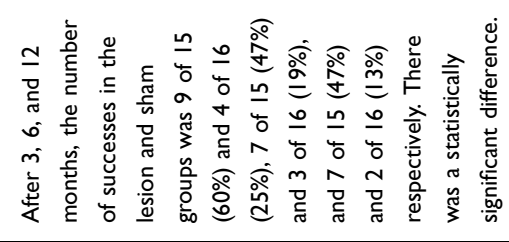 \\
\hline 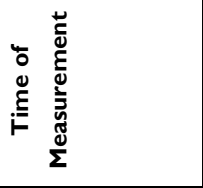 & & 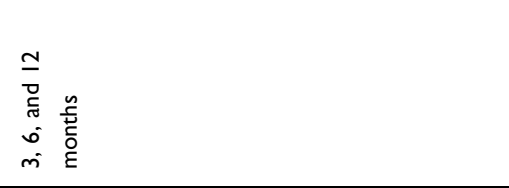 \\
\hline 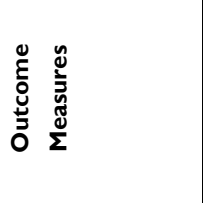 & 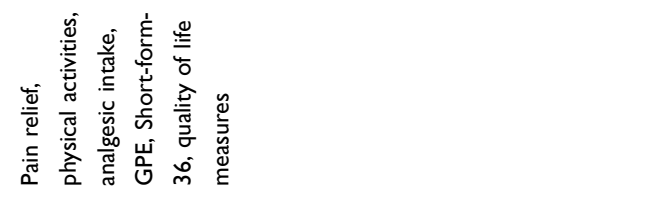 & 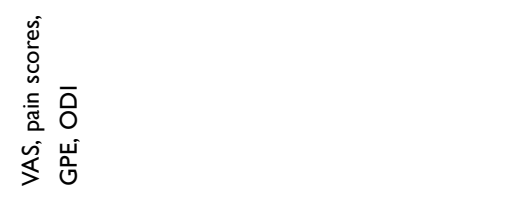 \\
\hline 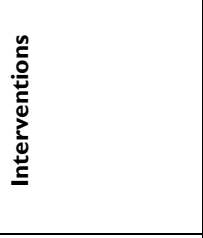 & 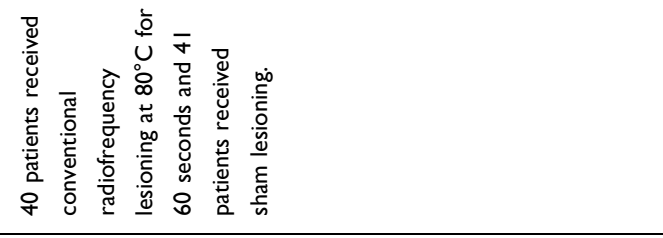 & 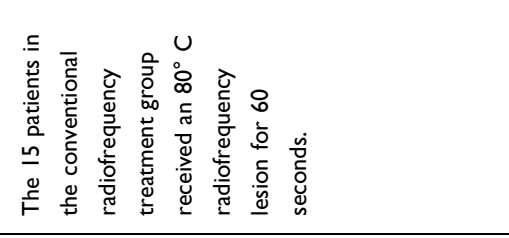 \\
\hline & 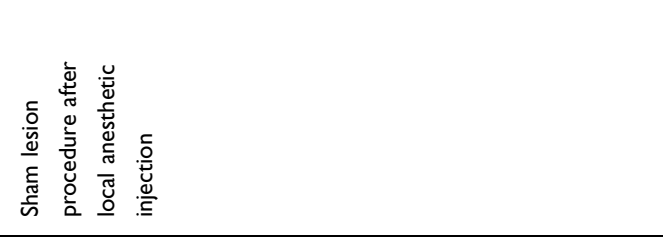 & 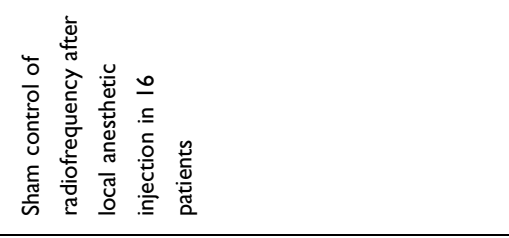 \\
\hline 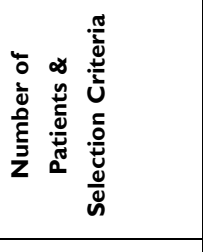 & 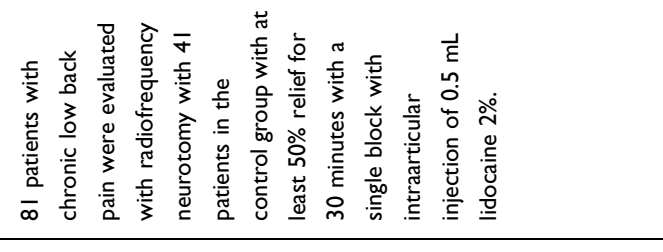 & 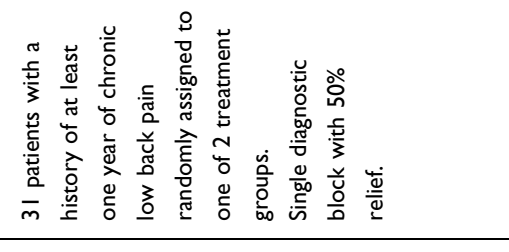 \\
\hline 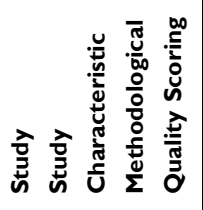 & 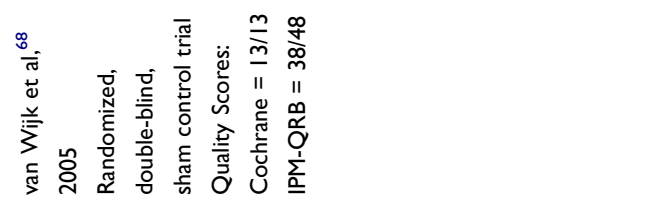 & 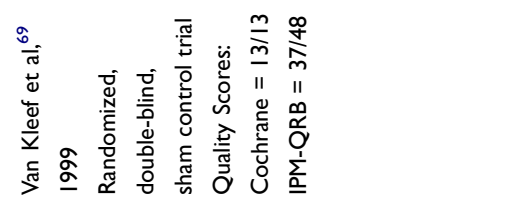 \\
\hline
\end{tabular}




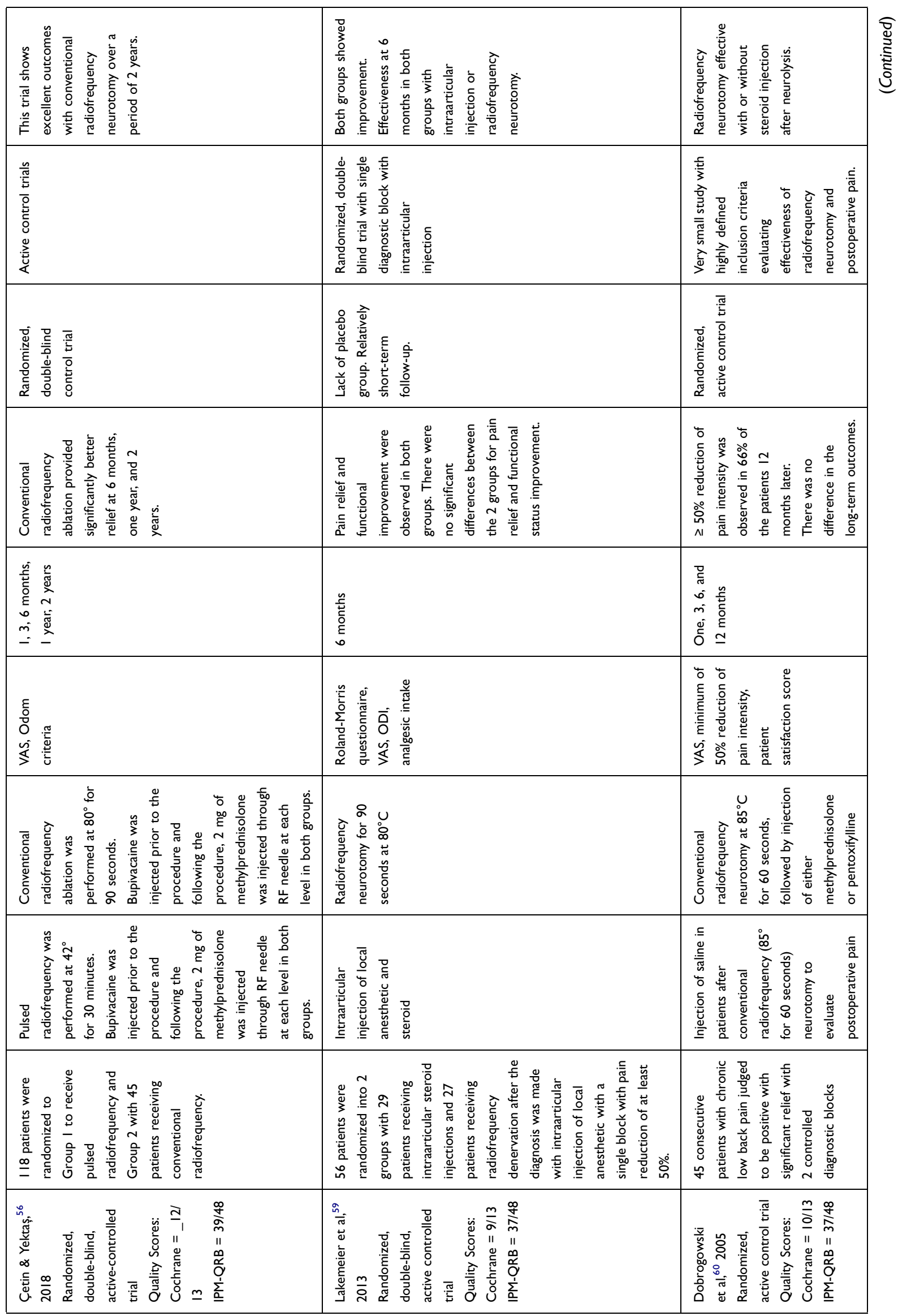




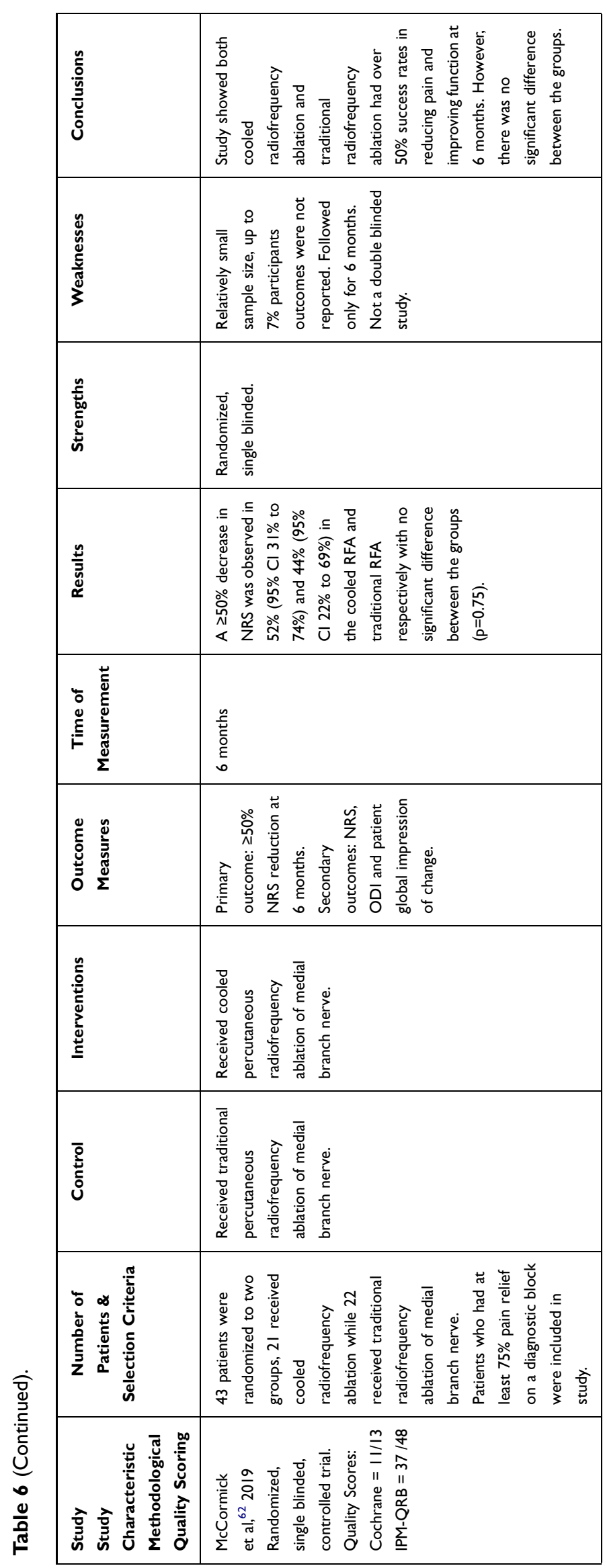




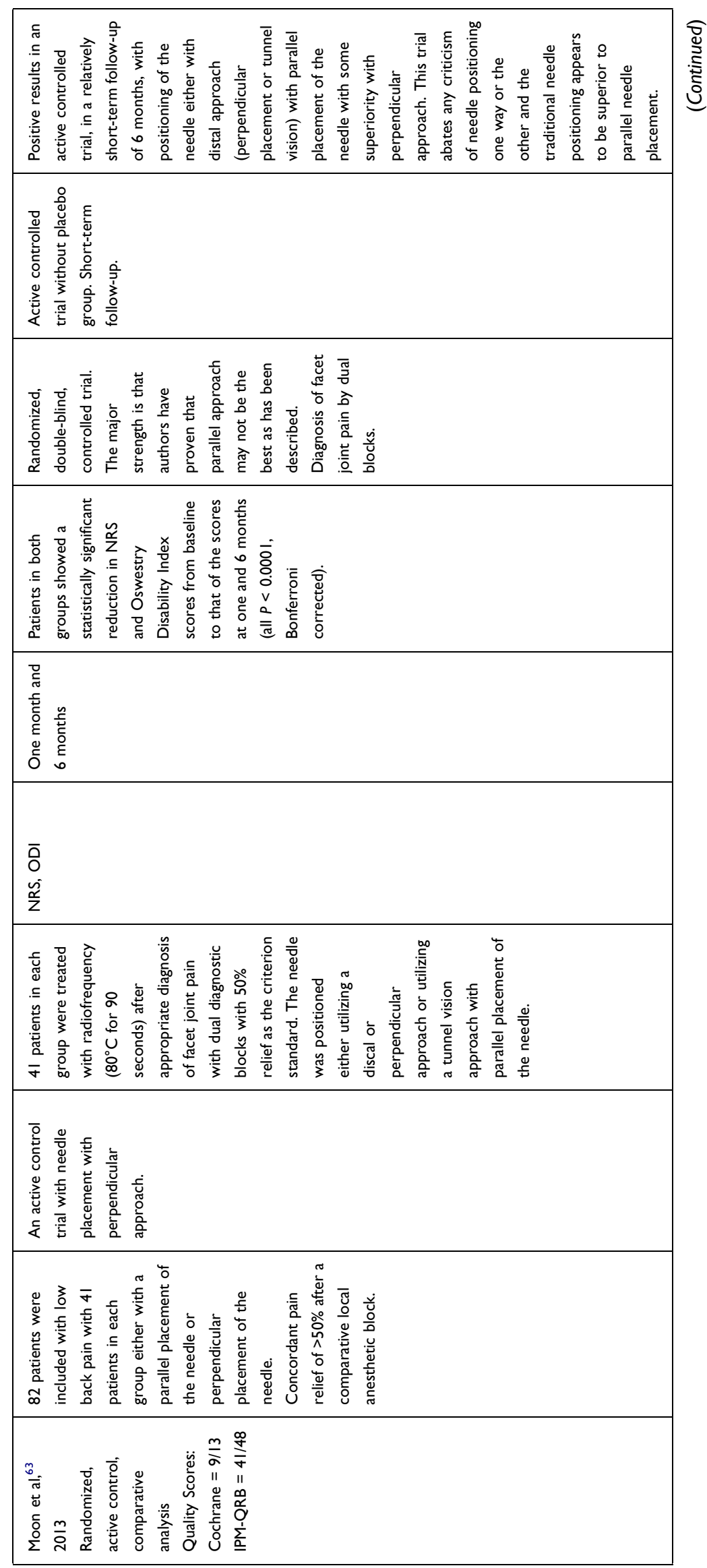




\begin{tabular}{|c|c|}
\hline 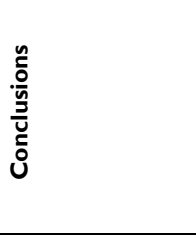 & 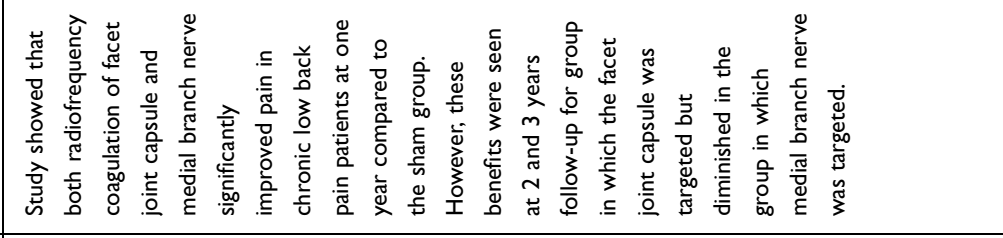 \\
\hline & 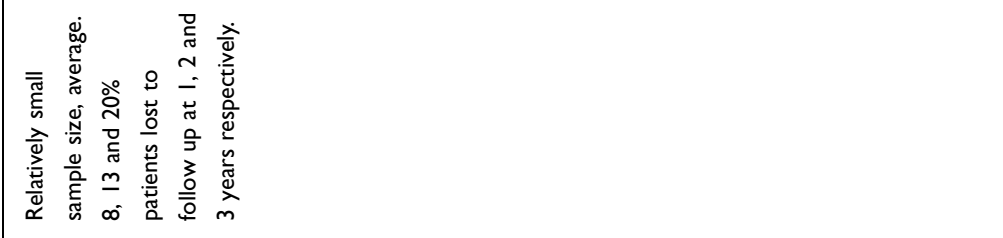 \\
\hline & 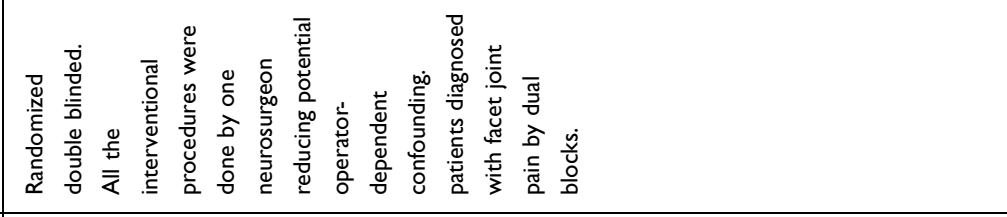 \\
\hline & 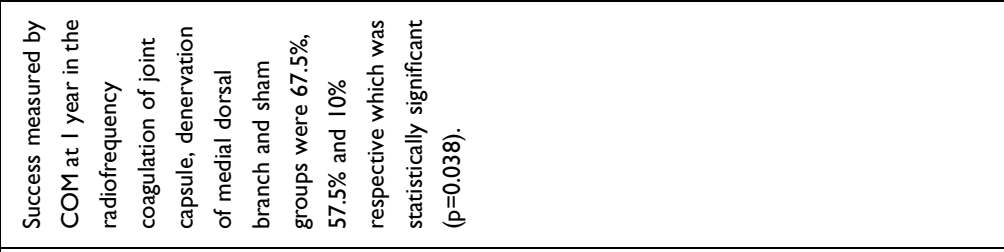 \\
\hline 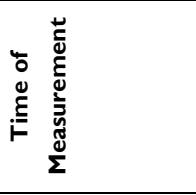 & 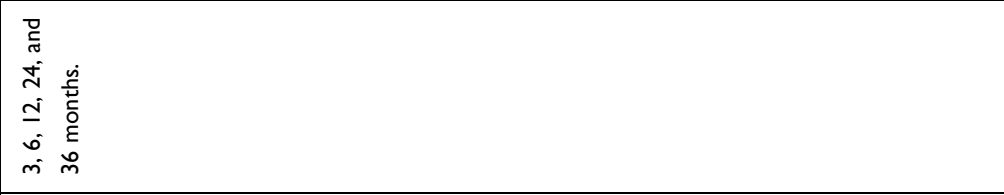 \\
\hline 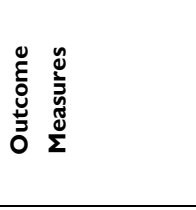 & 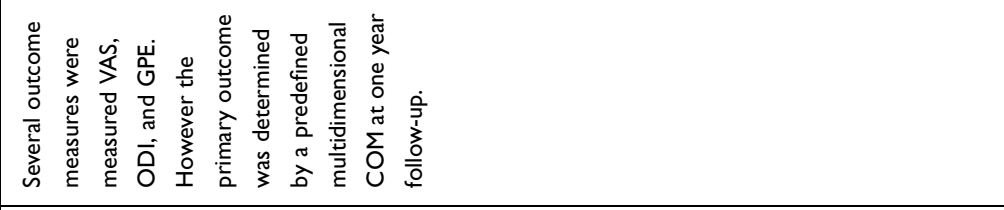 \\
\hline & 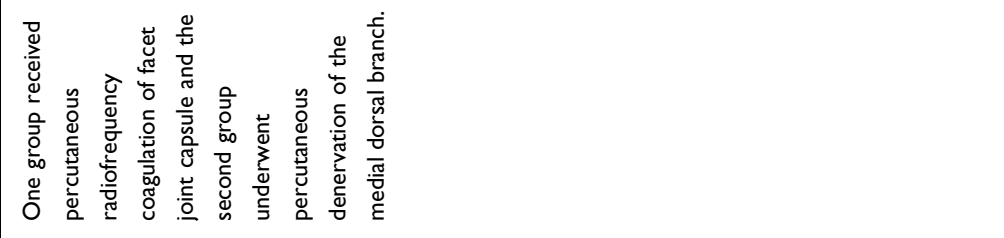 \\
\hline & 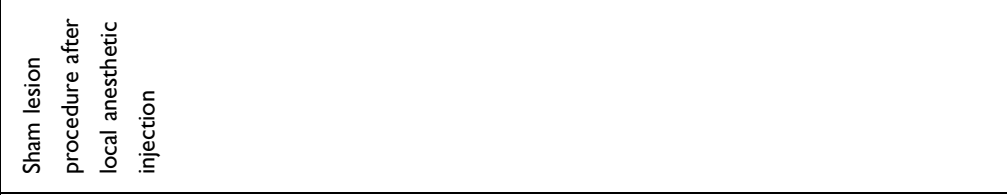 \\
\hline 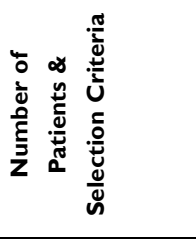 & 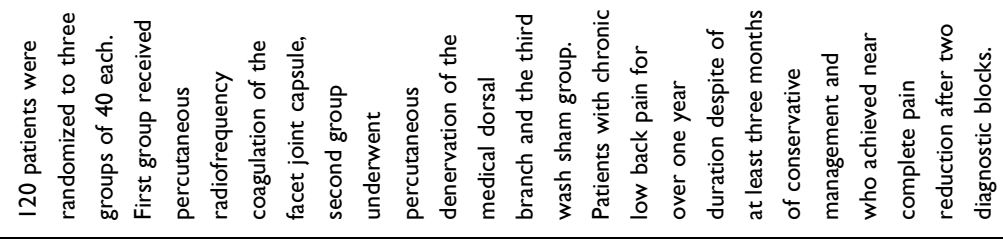 \\
\hline 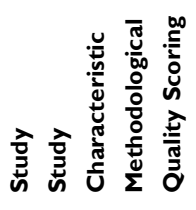 & 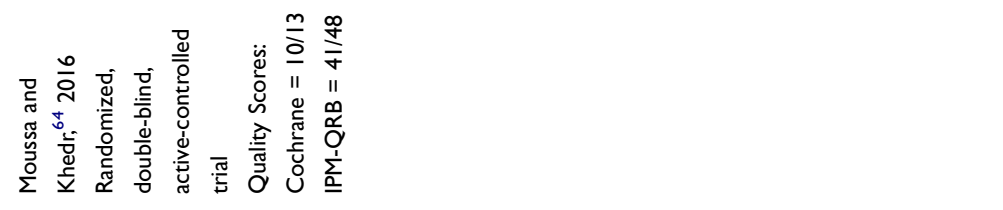 \\
\hline
\end{tabular}




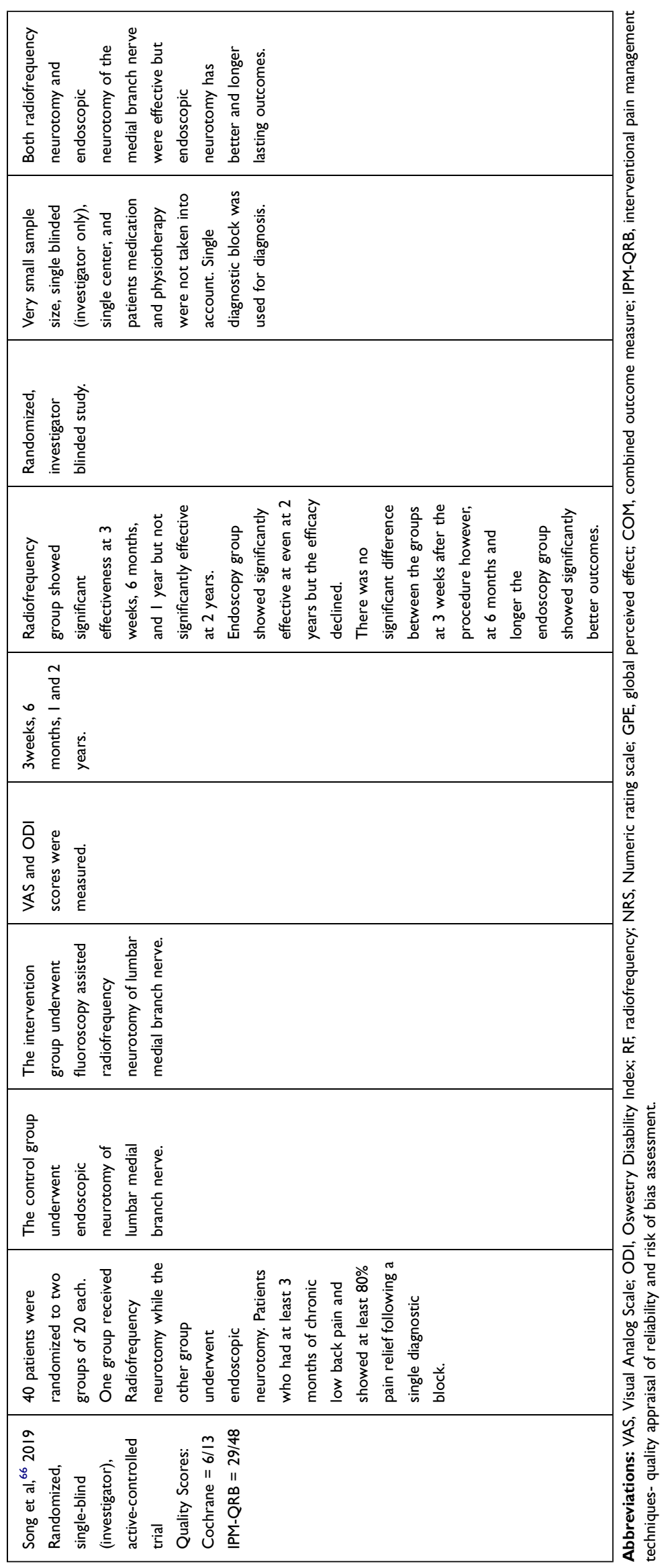




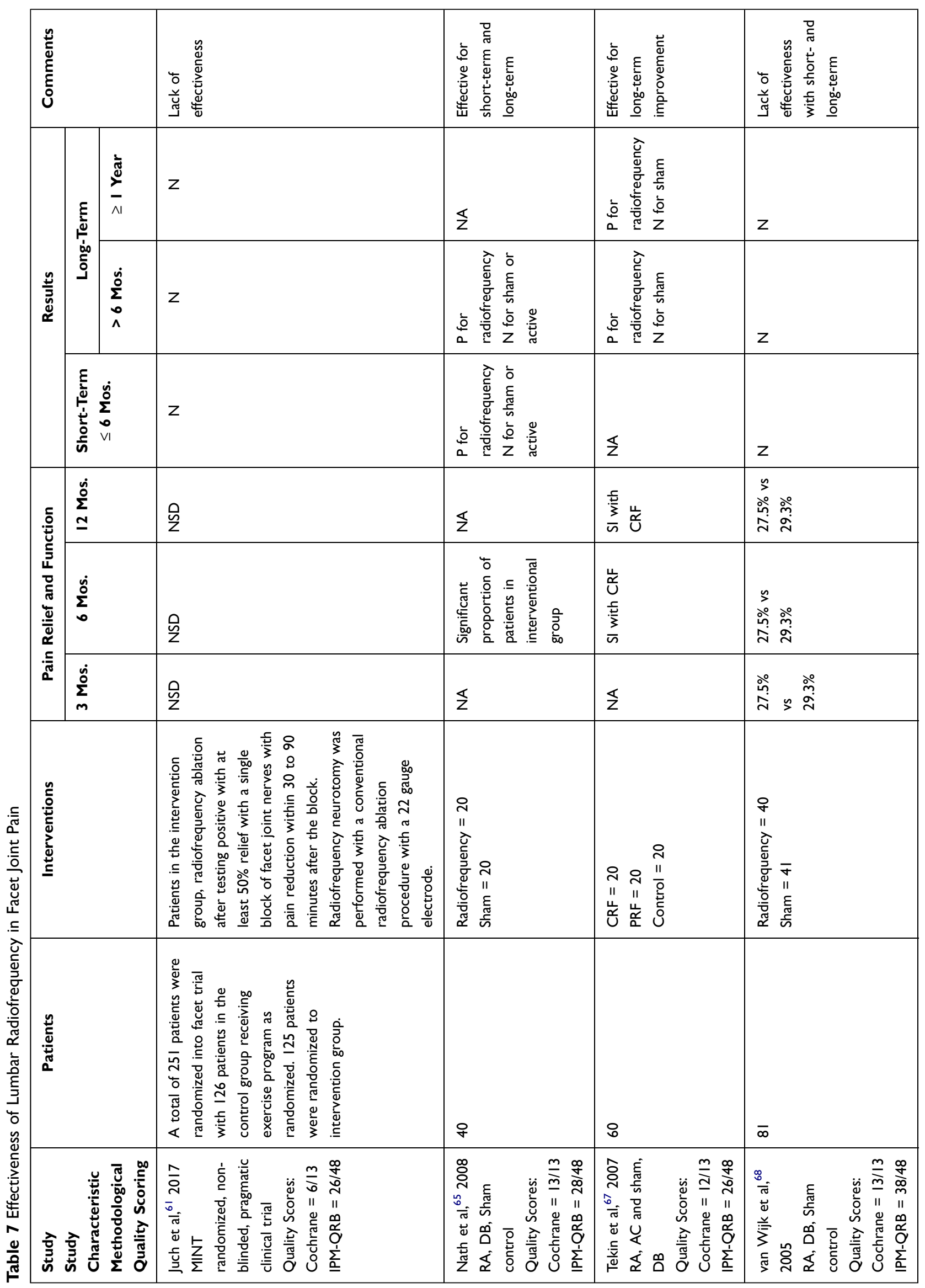




\begin{tabular}{|c|c|c|c|c|}
\hline 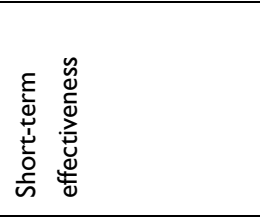 & 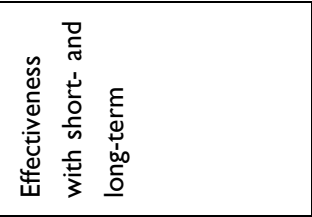 & 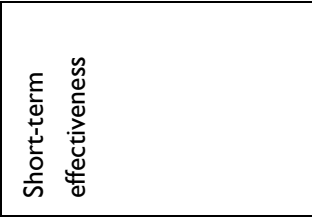 & 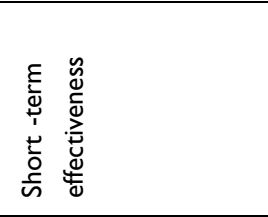 & 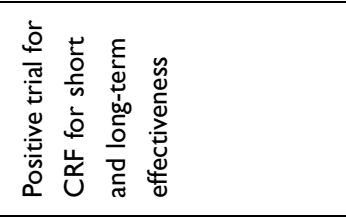 \\
\hline z & 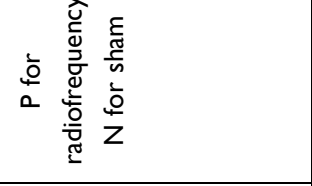 & $\mathbb{z}$ & $\Sigma$ & a \\
\hline a & 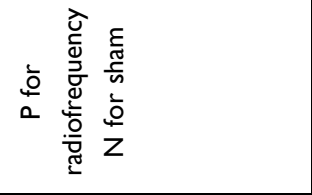 & a & a & a \\
\hline 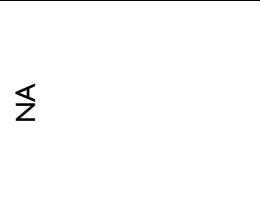 & 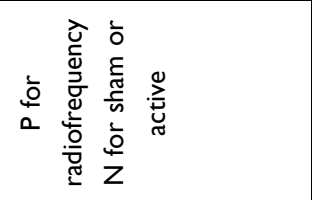 & a & a & a \\
\hline $\mathbb{z}$ & 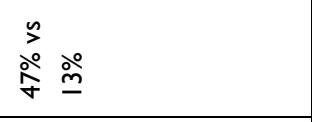 & $\underline{z}$ & $\underline{z}$ & $\bar{n}$ \\
\hline 亏̊̊̊ & 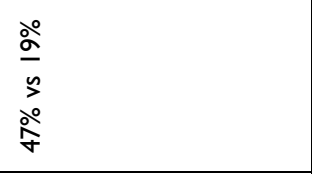 & 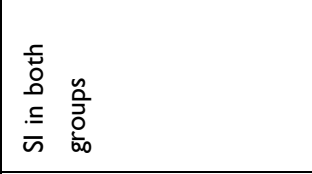 & 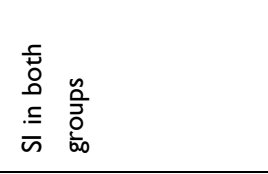 & क \\
\hline$\S$ & 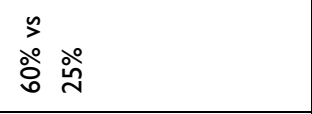 & 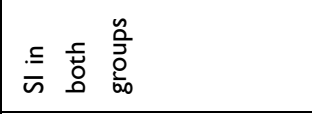 & $\mathbb{z}$ & क \\
\hline Ư & 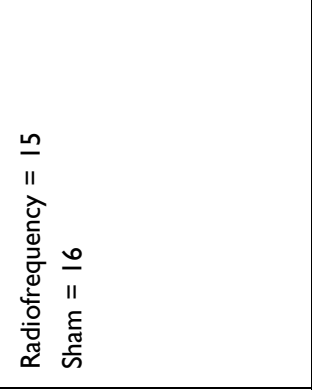 & 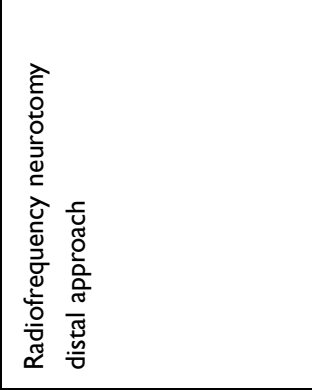 & 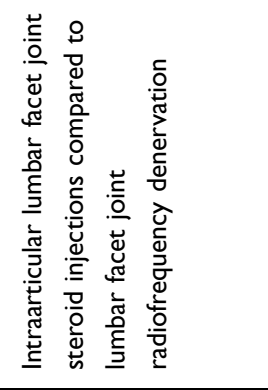 & 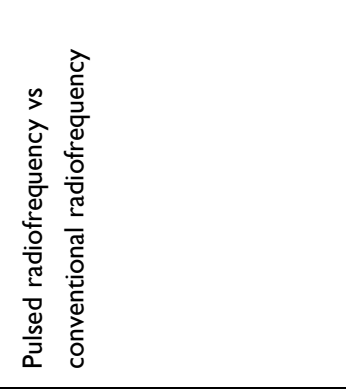 \\
\hline ケ & $\bar{m}$ & 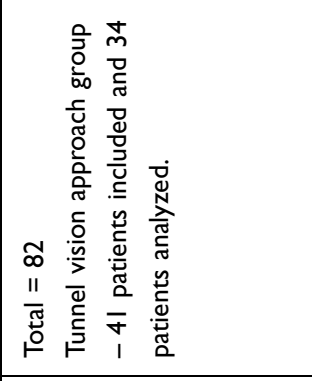 & 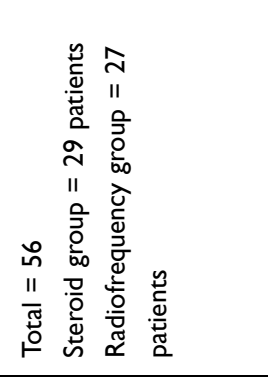 & 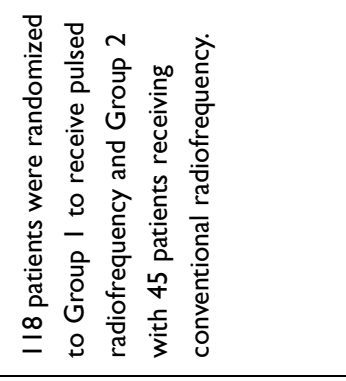 \\
\hline 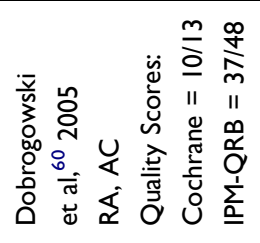 & 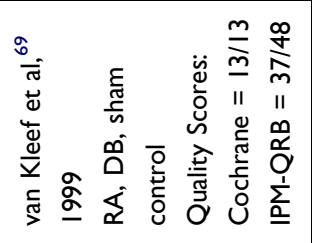 & 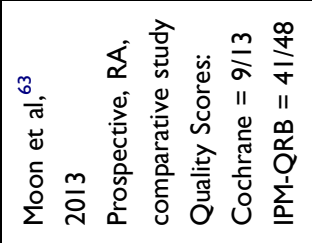 & 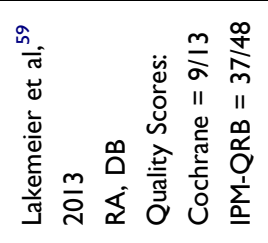 & 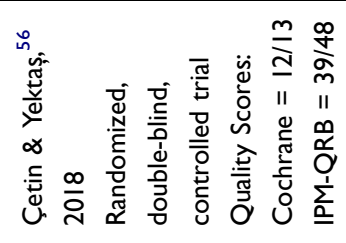 \\
\hline
\end{tabular}




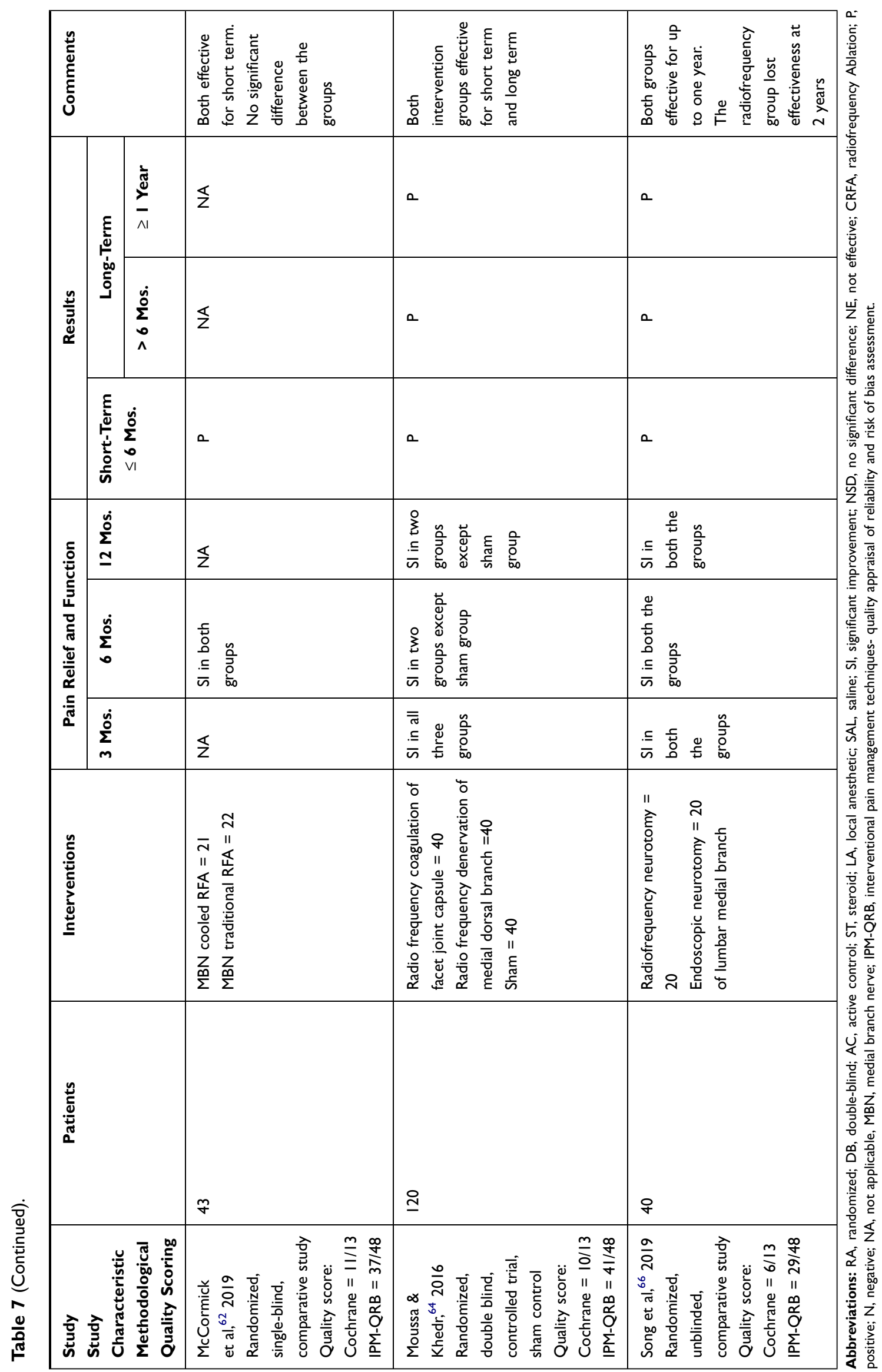




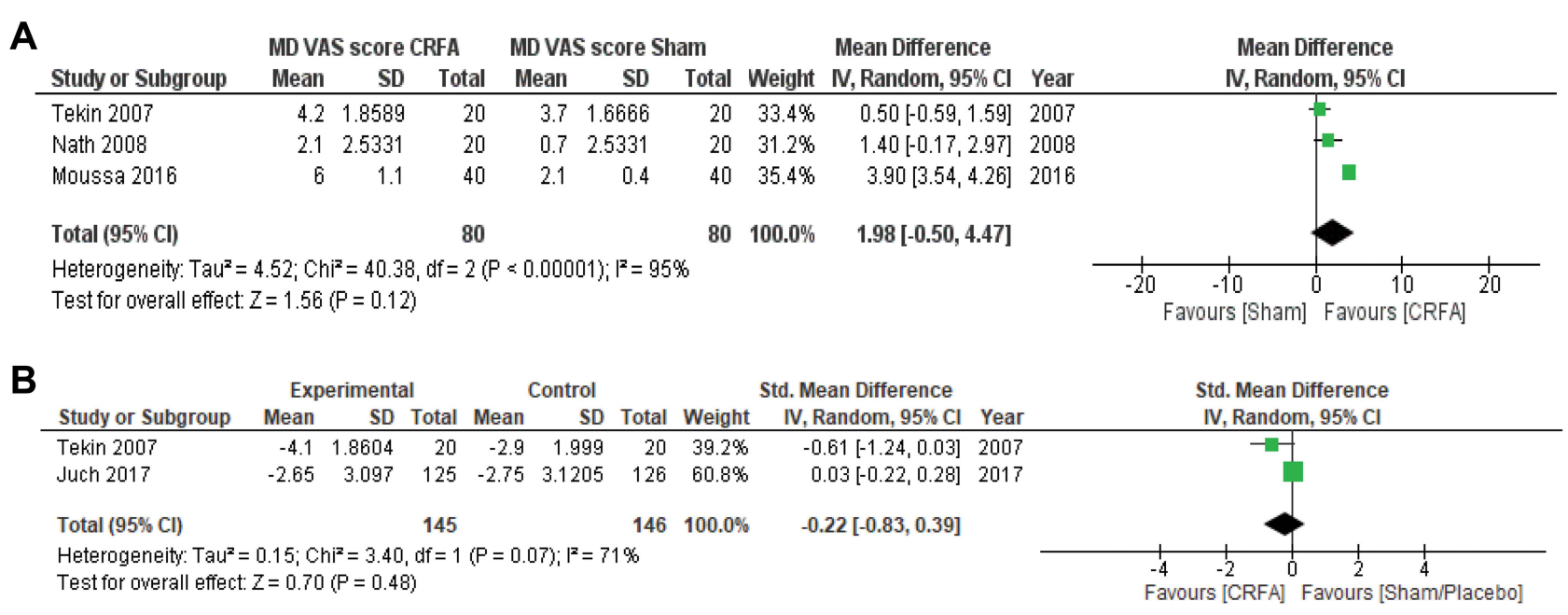

Figure 2 (A) Conventional dual-arm meta-analysis of pain relief of radiofrequency neurotomy vs sham control group at 6-month follow-up. (B) Conventional dual-arm meta-analysis of pain relief of radiofrequency neurotomy vs sham control group at 12-month follow-up.

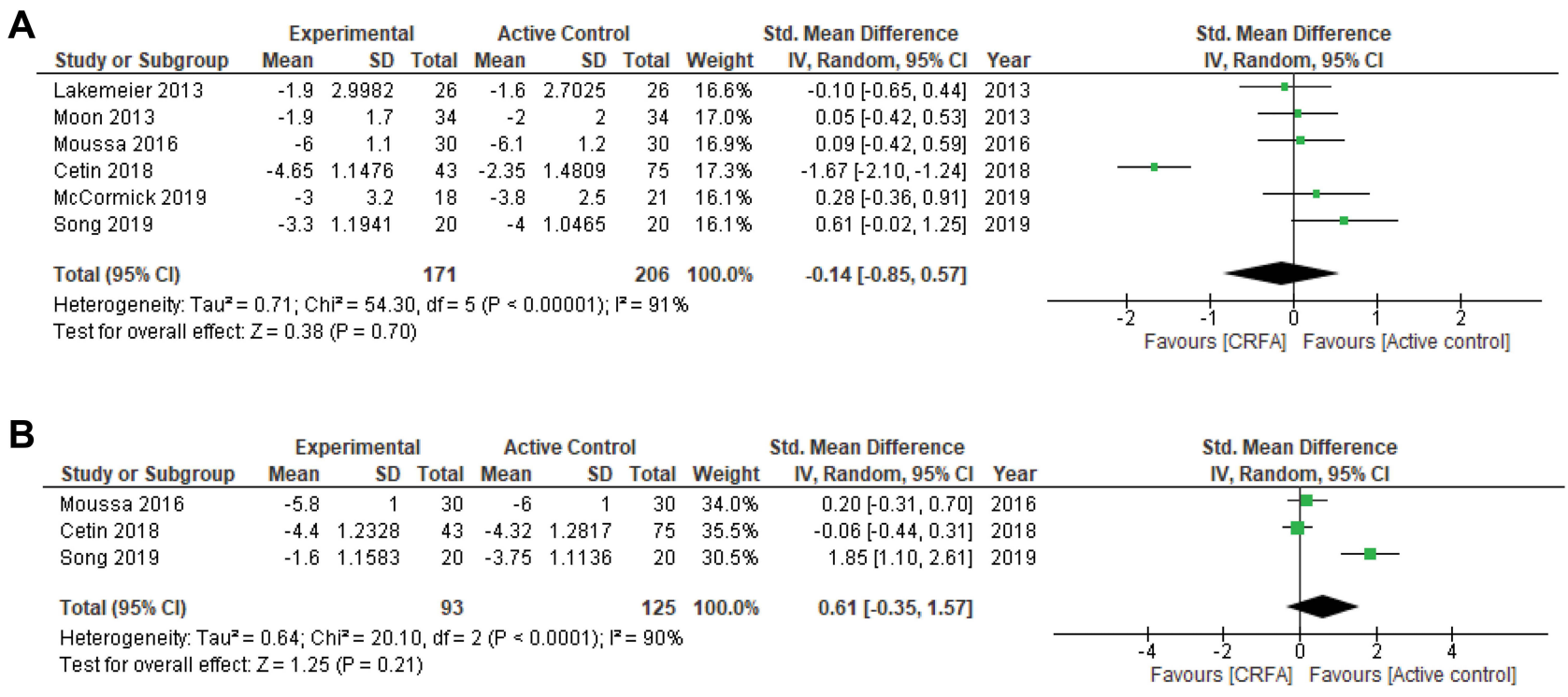

Figure 3 (A) Conventional dual-arm meta-analysis of pain relief of radiofrequency neurotomy of active control trials at 6 -month follow-up. (B) Conventional dual-arm meta-analysis of pain relief of radiofrequency neurotomy of active control trials at 12-month follow-up.

The evidence of efficacy based on dual-arm and singlearm meta-analysis of CRFA with placebo controlled and active controlled trials, is Level II evidence (moderate), in improving pain and function for short-term and long-term follow-up.

\section{Discussion}

This systematic review and meta-analysis of randomized trials of efficacy of lumbar facet joint radiofrequency neurotomy procedures in managing chronic low back pain revealed Level II evidence for short-term effectiveness of 6 months or less and for long-term effectiveness of 6 months or longer. Out of the 12 trials $^{56,59-69}$ included in this analysis, 6 trials ${ }^{56,64-67,69}$ demonstrated short- and long-term effectiveness, 4 trials $^{59,60,62,63}$ revealed short-term effectiveness only, whereas 2 trials ${ }^{61,68}$ showed lack of effectiveness. The evidence analysis for efficacy was based on five shamcontrolled trials, ${ }^{64,65,67-69}$ with one trial assessing shortterm outcomes (65) and four trials assessing long-term outcomes. ${ }^{64,67-69}$ Among these, five sham-controlled trials, three of them showed positive long-term outcomes, ${ }^{64,67,69}$ whereas one trial showed only shortterm positive outcomes. ${ }^{65}$ However, one trial ${ }^{68}$ showed 


\begin{tabular}{|c|c|c|c|c|c|c|c|c|c|c|c|}
\hline \multirow[b]{2}{*}{ Study or Subgroup } & \multicolumn{3}{|c|}{ Experimental } & \multicolumn{3}{|c|}{ Control } & \multicolumn{3}{|c|}{ Std. Mean Difference } & \multirow{2}{*}{\multicolumn{2}{|c|}{$\begin{array}{l}\text { Std. Mean Difference } \\
\text { IV, Random, } 95 \% \mathrm{Cl}\end{array}$}} \\
\hline & Mean & SD & Total & Mean & SD & Total & Weight & IV, Random, $95 \% \mathrm{Cl}$ & Year & & \\
\hline Tekin 2007 & -14.1 & 7.2941 & 20 & -11.2 & 6.3504 & 20 & $13.5 \%$ & $-0.42[-1.04,0.21]$ & 2007 & & \\
\hline Juch 2017 & -9.69 & 22.1102 & 125 & -7.24 & 21.3297 & 126 & $86.5 \%$ & $-0.11[-0.36,0.14]$ & 2017 & & \\
\hline Total $(95 \% \mathrm{Cl})$ & & & 145 & & & 146 & $100.0 \%$ & $-0.15[-0.38,0.08]$ & & & \\
\hline \multicolumn{10}{|c|}{$\begin{array}{l}\text { Heterogeneity: } \text { Tau }^{2}=0.00 ; \mathrm{Chi}^{2}=0.78, \mathrm{df}=1(\mathrm{P}=0.38) ; \mathrm{I}^{2}=0 \% \\
\text { Test for overall effect: } Z=1.30(P=0.19)\end{array}$} & -2 & $\begin{array}{cccc}1 & 1 & 1 & 1 \\
\text { Favours [CRFA] } & \text { Favours [Sham/Placebo] }\end{array}$ \\
\hline & \multicolumn{3}{|c|}{ Experimental } & \multicolumn{3}{|c|}{ Control } & \multicolumn{3}{|c|}{ Std. Mean Difference } & \multirow{2}{*}{\multicolumn{2}{|c|}{$\begin{array}{l}\text { Std. Mean Difference } \\
\text { IV, Random, } 95 \% \mathrm{Cl}\end{array}$}} \\
\hline Study or Subgroup & Mean & SD & Total & Mean & SD & Total & Weight & IV, Random, $95 \% \mathrm{Cl}$ & Year & & \\
\hline Tekin 2007 & -11.2 & 7.9157 & 20 & -6.5 & 6.3504 & 20 & $37.2 \%$ & $-0.64[-1.28,-0.00]$ & 2007 & & \\
\hline Juch 2017 & -10.48 & 23.273 & 125 & -9.35 & 22.221 & 126 & $62.8 \%$ & $-0.05[-0.30,0.20]$ & 2017 & & \\
\hline Total $(95 \% \mathrm{Cl})$ & & & 145 & & & 146 & $100.0 \%$ & $-0.27[-0.83,0.29]$ & & & \\
\hline \multicolumn{10}{|c|}{$\begin{array}{l}\text { Heterogeneity: } \operatorname{Tau}^{2}=0.11 ; \mathrm{Ch}^{2}=2.89, \mathrm{df}=1(\mathrm{P}=0.09) ; \mathrm{I}^{2}=65 \% \\
\text { Test for overall effect: } Z=0.94(P=0.35)\end{array}$} & -4 & $\begin{array}{cccc}1 & 1 & 1 & 1 \\
\text { Favours [CRFA] } & 0 & 2 & 4 \\
\text { Favours [Sham/Placebo] }\end{array}$ \\
\hline
\end{tabular}

Figure 4 (A) Conventional dual-arm meta-analysis of functional status (ODI) of radiofrequency neurotomy vs sham control group at 6-month follow-up. (B) Conventional dual-arm meta-analysis of functional status (ODI) of radiofrequency neurotomy vs sham control group at I2-month follow-up.

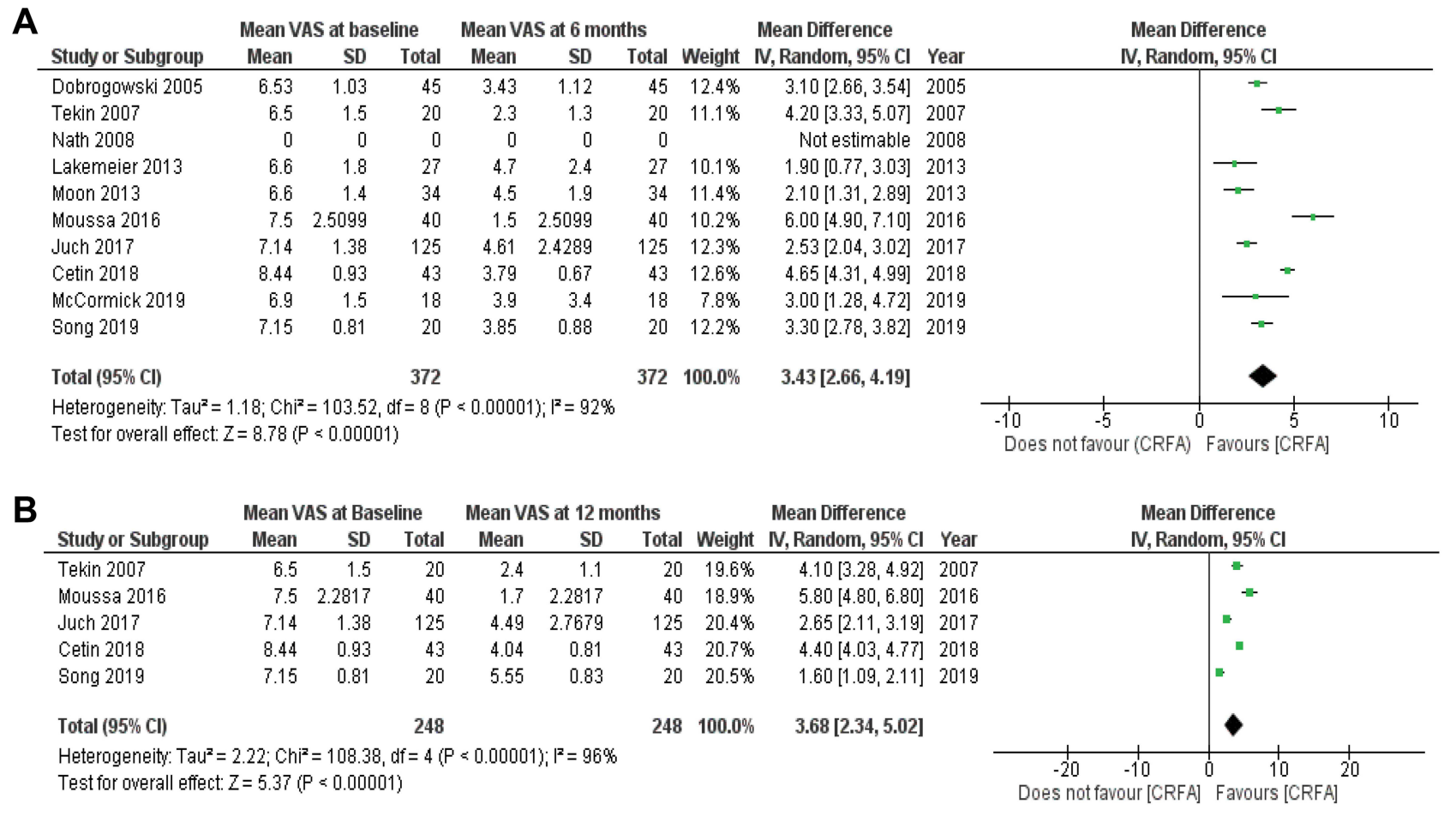

Figure 5 (A) Single arm meta-analysis of pain relief of radiofrequency neurotomy at baseline vs at 6-month follow-up of active-controlled trials. (B) Single arm meta-analysis of pain relief of radiofrequency neurotomy at baseline vs at 12-month follow-up of active control trials.

negative results for both short term and long term. Consequently, among the five studies, three showed long-term improvement and four showed short-term improvement. These results were strengthened by active-controlled trials with single-arm meta-analysis. However, among the studies which showed negative results, Juch et $\mathrm{al}^{61}$ included 251 patients with 126 patients in the control group. Even though the study had a variety of limitations, ${ }^{71-78}$ it is considered as one of the important studies in the literature. A second high-quality trial also showed lack of significant improvement with radiofrequency neurotomy. ${ }^{68}$ Thus, even though results are seen and positive results were demonstrated in 10 trials, the total number of patients undergoing conventional radiofrequency neurotomy were 296 of 717 . In contrast, among the two negative 


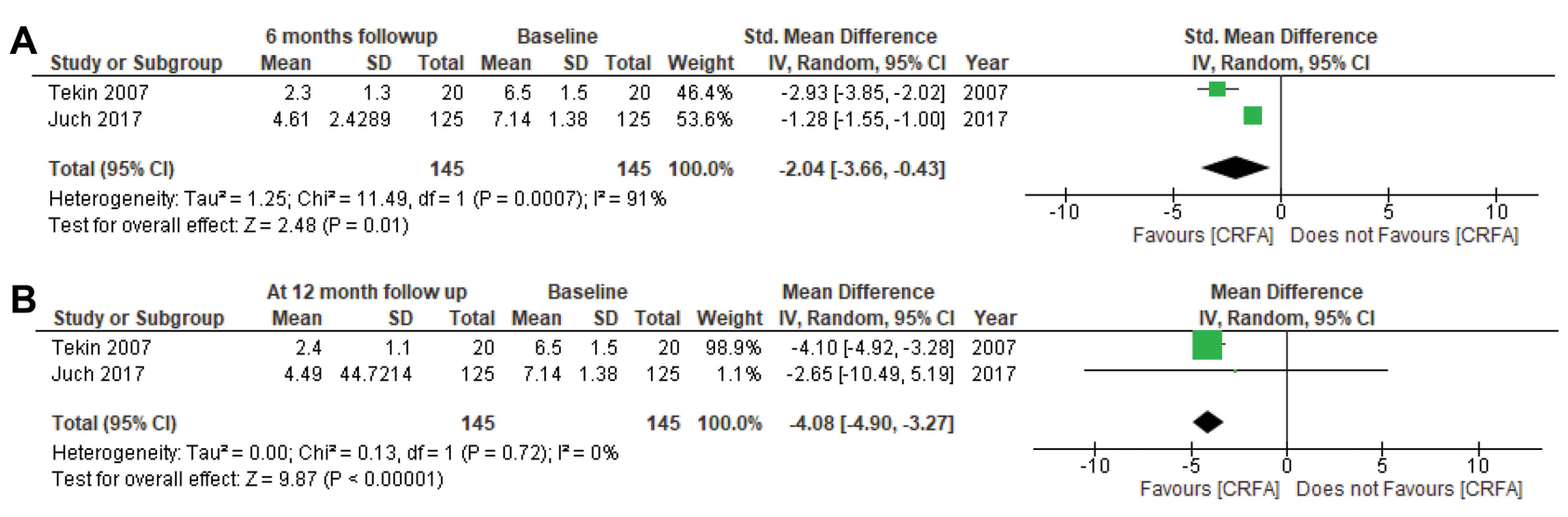

Figure 6 (A) Single-arm meta-analysis of functional status (ODI) of radiofrequency neurotomy at 6-month follow-up in sham control trials. (B) Single-arm meta-analysis of functional status (ODI) of radiofrequency neurotomy at 12 month follow-up in sham control trials.

trials, ${ }^{61,68} 162$ of 332 patients underwent radiofrequency neurotomy. The negative studies were larger than any of the positive studies in inclusion of the number of patients included in the study. Consequently, the evidence is Level II with positive results among 10 of the 12 trials and 2 negative trials.

The results of the present analysis are similar but nonetheless different from other previously published systematic reviews and guidelines. The guidelines for facet joint interventions ${ }^{3}$ showed Level II evidence for radiofrequency neurotomy in the lumbar spine with inclusion of a total of 11 trials, with 2 of them showing lack of effectiveness. However, two of the studies included in the guidelines were not included in this systematic review. There are additional studies which were not included in the systematic review/guidelines ${ }^{3}$ and included in the present review. In the systematic review and guidelines (3), the authors utilized 11 trials with the same 2 trials showing negative results and 9 trials showing positive results, The guidelines included both active-control and sham-control trials similar to the present manuscript. Overall, the results agree with this publication. The results of two additional systematic reviews by the same authors ${ }^{39,40}$ were also similar to the present study.

There are other systematic reviews which provide discordant opinions. Maas et $\mathrm{al}^{50}$ showed lack of effectiveness. Schneider et $\mathrm{al}^{49}$ showed effectiveness in patients with $100 \%$ pain relief and utilizing a parallel needle placement with relief in approximately $57 \%$ of the patients. Lee et $\mathrm{al}^{48}$ in a meta-analysis, concluded that conventional radiofrequency denervation resulted in a significant reduction in low back pain with positive results when compared with sham procedures over a period of 1 year. The analysis was performed in 231 patients from multiple studies undergoing denervation procedures. Leggett et $\mathrm{al}^{79}$ in an older systematic review analyzed six sham controlled RCTs performed between 1994 and 2008. They found high variability in selection criteria and outcomes with inconclusive effectiveness. In contrast, Poetscher et $\mathrm{al}^{80}$ also evaluated nine RCTs comparing the effect of radiofrequency treatment with other forms of treatment and with placebo and found that radiofrequency denervation was more effective than placebo and steroid injection. However, they concluded that evidence should be interpreted with caution.

In this review, $40 \%$ of the trials (5 of 12) compared CRFA to sham procedures. The majority of the trials ( 7 of 12) compared them to other interventions or a different mode of radiofrequency ablation. Lakemeier et al ${ }^{59}$ compared CRFA with intraarticular facet joint steroid injections, but only studied short-term effectiveness. This trial showed a positive result for both conventional radiofrequency and intraarticular steroid injections in short term. Two trials ${ }^{56,67}$ compared conventional radiofrequency to pulsed radiofrequency ablation. In both the studies, conventional radiofrequency demonstrated positive results, while pulsed radiofrequency ablation showed limited effectiveness. One trial ${ }^{66}$ compared CRFA to endoscopic neurotomy. In this trial, both the groups showed positive results in short term and long term according to our established criteria. However, the effectiveness of endoscopic neurotomy lasted for over 2 years while it did not in the CRFA group. Overall, CRFA appears to be effective in 
both the short term and long term as an intervention in chronic low back pain of facet joint origin.

From the meta-analysis, though there was no statistical difference of pain VAS score between CRFA and sham procedure at 6 months follow-up, there was a trend towards CRFA being more effective than a sham procedure. These results might in part be related to the small sample sizes of the RCTs, with a cumulative sample size of just 160 patients with 80 in each arm. Thus, more studies with larger patient sample sizes should be conducted to establish the effectiveness of lumbar radiofrequency neurotomy. However, in single-arm analysis, the radiofrequency neurotomy using CRFA showed a statistically significant reduction in the pain VAS scores both at 6 months and 12 months follow-up compared to the baseline.

As with any systematic review and meta-analysis, the validity of this analysis is only as reliable as the validity of the primary studies. Although there were multiple studies in this meta-analysis the patient sample size was low in most of the primary studies.

Multiple issues have been highlighted in reference to the systematic reviews, specifically in interventional pain management, ${ }^{3,4,21,81-84}$ Significant controversy related to placebo and multiple issues related to metaanalysis of active control trials have been discussed. Manchikanti et $\mathrm{al}^{81}$ have shown sodium chloride solution injected into the epidural space is not a placebo. Similarly, they have shown epidural lidocaine is also not a placebo. ${ }^{26}$ In this assessment, local anesthetic was utilized during sham control. This can provide relief, which can be significant. ${ }^{3}$ Consequently, in a dual-arm meta-analysis, it is difficult to assess the role of effectiveness of conventional radiofrequency neurotomy when local anesthetic was utilized prior to sham neurolysis, as well as when an active control was utilized. This affects all placebo and sham control trials, as well as active control trials. None of the previous reviews have performed a single-arm analysis. It has been shown that is crucial to perform a single-arm analysis in multiple studies as expected in this systematic review and meta-analysis., ${ }^{3,26,27,81-84}$ Qualitative analysis demonstrated positive results with Level II evidence. Quantitative analysis also showed Level II evidence with dual-arm analysis. However, single-arm analysis meta-analysis showed clear superiority of conventional radiofrequency neurotomy compared to local anesthetic injection or other treatments including pulsed radiofrequency. Though not appreciated well, singlearm analysis is crucial in elucidating the effectiveness of both groups, whether it is local anesthetic converted into placebo or local anesthetic administered prior to sham procedure. Consequently, differences in conclusions may be the product of methodological differences between investigators. ${ }^{3,4,26,81-93}$

\section{Conclusion}

This systematic review provides evidence variable from Level II for short-term and long-term effectiveness of radiofrequency neurotomy, diagnosed with controlled diagnostic blocks. Overall, the evidence was adjusted to Level II based on the negative studies with large sample sizes.

\section{Acknowledgments}

The authors wish to thank Tonie M. Hatton and Diane E. Neihoff, transcriptionists, for their assistance in preparation of this manuscript.

\section{Author Contributions}

All authors made a significant contribution to the work reported, whether that is in the conception, study design, execution, acquisition of data, analysis and interpretation, or in all these areas; took part in drafting, revising or critically reviewing the article; gave final approval of the version to be published; have agreed on the journal to which the article has been submitted; and agree to be accountable for all aspects of the work.

\section{Funding}

There was no external funding in preparation of this manuscript.

\section{Disclosure}

Dr Abd-Elsayed is a consultant of Medtronic and Avanos and reports no other potential conflicts of interest for this work. Dr Hirsch is a consultant for Medtronic and Senior Affiliate Research Fellow at the Neiman Policy Institute and reports personal fees from Medtronic, Persica, and Relevant and grants from Neiman Health Policy Institute, outside the submitted work, and reports no other potential conflicts of interest for this work. All other authors report no conflicts of interest in this work. 


\section{References}

1. Dieleman JL, Baral R, Birger M, et al. US spending on personal health care and public health, 1996-2013. JAMA. 2016;316 (24):2627-2646. doi:10.1001/jama.2016.16885

2. Dieleman JL, Cao J, Chapin A, et al. US health care spending by payer and health condition, 1996-2016. JAMA. 2020;323(9):863884. doi:10.1001/jama.2020.0734

3. Manchikanti L, Kaye AD, Soin A, et al. Comprehensive evidencebased guidelines for facet joint interventions in the management of chronic spinal pain: American Society of Interventional Pain Physicians (ASIPP) guidelines. Pain Physician. 2020;23(3S):S1S127. doi:10.36076/ppj.2020/23/S1

4. Manchikanti L, Knezevic NN, Navani A, et al. Epidural interventions in the management of chronic spinal pain: American Society of Interventional Pain Physicians (ASIPP) comprehensive evidencebased guidelines. Pain Physician. 2021;24(S1):S27-S208.

5. Manchikanti L, Centeno CJ, Atluri S, et al. Bone marrow concentrate (BMC) therapy in musculoskeletal disorders: evidence-based policy position statement of American Society of Interventional Pain Physicians (ASIPP). Pain Physician. 2020;23(2):E85-E131.

6. U.S. Burden of Disease Collaborators. The state of US health, 1990 2010: burden of diseases, injuries, and risk factors. JAMA. 2013;310 (6):591-608. doi:10.1001/jama.2013.13805

7. Hoy DG, Bain C, Williams G, et al. A systematic review of the global prevalence of low back pain. Arthritis Rheum. 2012;64(6):20282037. doi:10.1002/art.34347

8. Manchikanti L, Sanapati MR, Pampati V, Boswell MV, Kaye AD, Hirsch JA. Update on reversal and decline of growth of utilization of interventional techniques in managing chronic pain in the Medicare population from 2000 to 2018. Pain Physician. 2019;22(6):521-536. doi:10.36076/ppj/2019.22.521

9. Manchikanti L, Soin A, Mann DP, et al. Utilization patterns of facet joint interventions in managing spinal pain: a retrospective cohort study in the US fee-for-service medicare population. Curr Pain Headache Rep. 2019;23(10):73. doi:10.1007/s11916-0190816-7

10. Manchikanti L, Soin A, Mann DP, Bakshi S, Pampati V, Hirsch JA. Comparative analysis of utilization of epidural procedures in managing chronic pain in the medicare population: pre and post affordable care act. Spine (Phila Pa 1976). 2019;44(3):220-232. doi:10.1097/ BRS.0000000000002785

11. Manchikanti L, Pampati V, Soin A, et al. Trends of expenditures and utilization of facet joint interventions in fee-for-service (FFS) medicare population from 2009-2018. Pain Physician. 2020;23(3S): S129-S147. doi:10.36076/ppj.2020/23/S129

12. Manchikanti L, Pampati V, Soin A, Sanapati MR, Kaye AD, Hirsch JA. Declining utilization and inflation-adjusted expenditures for epidural procedures in chronic spinal pain in the medicare population. Pain Physician. 2021;24(1):1-15.

13. Wagemakers SH, van der Velden JM, Gerlich AS, et al. A systematic review of devices and techniques that objectively measure patients' pain. Pain Physician. 2019;22(1):1-13.

14. La Touche R, Grande-Alonso M, Arnes-Prieto P, Paris-Alemany A. How does self-efficacy influence pain perception, postural stability and range of motion in individuals with chronic low back pain? Pain Physician. 2019;22(1):E1-E13. doi:10.36076/ $\mathrm{ppj} / 2019.22$.E1

15. Coulter ID, Crawford C, Vernon H, et al. Manipulation and mobilization for treating chronic nonspecific neck pain: a systematic review and meta-analysis for an appropriateness panel. Pain Physician. 2019;22(2):E55-E70. doi:10.36076/ppj/2019.22.E55

16. Bansal D, Asrar MM, Ghai B, Pushpendra D. Prevalence and impact of low back pain in a community-based population in Northern India. Pain Physician. 2020;23(4):E389-E398. doi:10.36076/ppj.2020/23/ E389
17. Manchikanti L, Vanaparthy R, Atluri S, Sachdeva H, Kaye AD, Hirsch JA. COVID-19 and the opioid epidemic: two public health emergencies that intersect with chronic pain. Pain Ther. 2021;10:269-286. doi:10.1007/s40122-021-00243-2

18. U.S. Department of Health and Human Services, Office of Inspector General. Medicare improperly paid physicians for more than five spinal facet-joint injection sessions during a rolling 12-month period (A-09-20-03003); 2020. Available from: https://oig.hhs.gov/oas/ reports/region9/92003003.asp. Accessed March 24, 2021.

19. U.S. Department of Health and Human Services, Office of Inspector General. Noridian healthcare solutions, LLC, made improper medicare payments of $\$ 4$ million to physicians in jurisdiction $\mathrm{E}$ for spinal facetjoint injections (A-09-20-03010); 2021. Available from: https://oig.hhs. gov/oas/reports/region9/92003010.asp. Accessed March 4, 2021.

20. Medical Policy, CGS Administrators LLC. Multi-jurisdictional contractor advisory committee (CAC) meeting. Facet joint and medial nerve branch procedures; 2020.

21. National Government Services, Inc. Local coverage determination (LCD). Facet joint interventions for pain management (L35936); 2021.

22. Manchikanti L, Singh V, Kaye AD, Hirsch JA. Lessons for better pain management in the future: learning from the past. Pain Ther. 2020;9(2):373-391. doi:10.1007/s40122-020-00170-8

23. Shah S, Diwan S, Soin A, et al. Evidence-based risk mitigation and stratification during COVID-19 for return to interventional pain practice: American Society of Interventional Pain Physicians (ASIPP) guidelines. Pain Physician. 2020;23(4S):S161-S182. doi:10.36076/ppj.2020/23/S161

24. Gharibo C, Sharma A, Soin A, et al. Triaging interventional pain procedures during COVID-19 or related elective surgery restrictions: evidence-informed guidance from the American Society of Interventional Pain Physicians (ASIPP). Pain Physician. 2020;23 (4S):S183-204. doi:10.36076/ppj.2020/23/S183

25. Wahezi SE, Duarte RA, Yerra S, et al. Telemedicine during COVID19 and beyond: a practical guide and best practices multidisciplinary approach for the orthopedic and neurologic pain physical examination. Pain Physician. 2020;23(4S):S205-S238.

26. Knezevic NN, Manchikanti L, Urits I, et al. Lack of superiority of epidural injections with lidocaine with steroids compared to without steroids in spinal pain: a systematic review and meta-analysis. Pain Physician. 2020;23(4S):S239-S270.

27. Manchikanti L, Kosanovic R, Vanaparthy R, et al. Steroid distancing in interventional pain management during COVID-19 and beyond: safe, effective and practical approach. Pain Physician. 2020;23(4S): S319-S350. doi:10.36076/ppj.2020/23/S319

28. Soin A, Vuppala S, Surfield G, et al. Ohio response to COVID-19 and its impact on interventional pain management practices. Pain Physician. 2020;23(4S):S439-S448. doi:10.36076/ppj.2020/23/S439

29. Singh JR, Miccio VF Jr, Modi DJ, Sein MT. The impact of local steroid administration on the incidence of neuritis following lumbar facet radiofrequency neurotomy. Pain Physician. 2019;22(1):69-74. doi:10.36076/ppj/2019.22.69

30. Bharti N, Sujith J, Singla N, Panda NB, Bala I. radiofrequency thermoablation of the gasserian ganglion versus the peripheral branches of the trigeminal nerve for treatment of trigeminal neuralgia: a randomized, control trial. Pain Physician. 2019;22(2):147-154. doi:10.36076/ppj/2019.22.147

31. LaGrew J, Balduyeu P, Vasilopoulos T, Kumar S. Incidence of cervicogenic headache following lower cervical radiofrequency neurotomy. Pain Physician. 2019;22(2):E127-E132.

32. Pearson ACS, Dexter F. Observational study of the distribution and diversity of interventional pain procedures among hospitals in the State of Iowa. Pain Physician. 2019;22(3):E157-E170.

33. Wang R, Ma C, Han Y, Tan M, Lu L. Effectiveness of denervation therapy on pain and joint function for patients with refractory knee osteoarthritis: a systematic review and meta-analysis. Pain Physician. 2019;22(4):341-352. 
34. Kapural L, Lee N, Neal K, Burchell M. Long-term retrospective assessment of clinical efficacy of radiofrequency ablation of the knee using a cooled radiofrequency system. Pain Physician. 2019;22(5):489-494. doi:10.36076/ppj/2019.22.489

35. Friedrich J, Itano EM, Lynn RR. Management of cardiac implantable electrical devices in patients undergoing radiofrequency ablation for spine pain: physician survey and review of guidelines. Pain Physician. 2020;23(4):E335-E342. doi:10.36076/ppj.2020/23/E335

36. Orhurhu V, Khan F, Quispe RC, et al. Use of radiofrequency ablation for the management of facial pain: a systematic review. Pain Physician. 2020;23(6):E559-E580.

37. Abarca TL, Dexter F, Epstein RH, Pearson ACS. Hospitals' web site lists of their interventional pain procedures inadequately reflect the diversity of their actual pain medicine practices. Pain Physician. 2020;23(6):E723-E730.

38. Boswell MV, Manchikanti L, Kaye AD, et al. A best-evidence systematic appraisal of the diagnostic accuracy and utility of facet (Zygapophysial) joint injections in chronic spinal pain. Pain Physician. 2015;18(4):E497-E533. doi:10.36076/ppj.2015/18/E497

39. Manchikanti L, Hirsch JA, Falco FJ, Boswell MV. Management of lumbar zygapophysial (facet) joint pain. World J Orthop. 2016;7 (5):315-337. doi:10.5312/wjo.v7.i5.315

40. Manchikanti L, Kaye AD, Boswell MV, et al. A systematic review and best evidence synthesis of effectiveness of therapeutic facet joint interventions in managing chronic spinal pain. Pain Physician. 2015;18(4):E535-E582. doi:10.36076/ppj.2015/18/E535

41. Kuslich SD, Ulstrom CL, Michael CJ. The tissue origin of low back pain and sciatica: a report of pain response to tissue stimulation during operations on the lumbar spine using local anesthesia. Orthop Clin North Am. 1991;22(2):181-187. doi:10.1016/S00305898(20)31644-8

42. Schwarzer AC, Aprill CN, Derby R, Fortin J, Kine G, Bogduk N. Clinical features of patients with pain stemming from the lumbar zygapophysial joints. Is the lumbar facet syndrome a clinical entity? Pine (Phila Pa 1976). 1994;19(10):1132-1137. doi:10.1097/ 00007632-199405001-00006

43. Manchikanti L, Singh V, Pampati V, et al. Evaluation of the relative contributions of various structures in chronic low back pain. Pain Physician. 2001;4(4):308-316. doi:10.36076/ppj.2001/4/308

44. DePalma MJ, Ketchum JM, Saullo T. What is the source of chronic low back pain and does age play a role? Pain Med. 2011;12(2):224233. doi:10.1111/j.1526-4637.2010.01045.x

45. MacVicar J, MacVicar AM, Bogduk N. The prevalence of "Pure" lumbar zygapophysial joint pain in patients with chronic low back pain. Pain Med. 2021;22(1):41-48. doi:10.1093/pm/pnaa383

46. Manchikanti L, Kosanovic R, Pampati V, et al. Low back pain and diagnostic lumbar facet joint nerve blocks: assessment of prevalence, false-positive rates, and a philosophical paradigm shift from an acute to a chronic pain model. Pain Physician. 2020;23(5):519-530. doi:10.36076/ppj.2020/23/519

47. Manchikanti L, Kosanovic R, Cash KA, et al. Assessment of prevalence of cervical facet joint pain with diagnostic cervical medial branch blocks: analysis based on chronic pain model. Pain Physician. 2020;23(6):531-540.

48. Lee $\mathrm{CH}$, Chung $\mathrm{CK}$, Kim $\mathrm{CH}$. The efficacy of conventional radiofrequency denervation in patients with chronic low back pain originating from the facet joints: a meta-analysis of randomized controlled trials. Spine J. 2017;17(11):1770-1780. doi:10.1016/j.spinee.2017. 05.006

49. Schneider BJ, Doan L, Maes MK, et al. Systematic review of the effectiveness of lumbar medial branch thermal radiofrequency neurotomy, stratified for diagnostic methods and procedural technique. Pain Med. 2020;21(6):1122-1141. doi:10.1093/pm/pnz349

50. Maas ET, Ostelo RW, Niemisto L, et al. Radiofrequency denervation for chronic low back pain. Cochrane Database Syst Rev. 2015;10: CD008572.
51. Page MJ, McKenzie JE, Bossuyt PM, Boutron I, Hoffmann TC, Mulrow CD, et al. The PRISMA 2020 statement: an updated guideline for reporting systematic reviews. BMJ. 2021;372:n71. http:// prisma-statement.org/. Accessed February 17, 2021. doi:10.1136/ bmj.n71

52. Liberati A, Altman DG, Tetzlaff J. et al. The PRISMA statement for reporting systematic reviews and meta-analyses of studies that evaluate health care interventions: explanation and elaboration. Ann Intern Med. 2009;151(4):W65-W94. doi:10.7326/0003-4819-151-4200908180-00136

53. Furlan AD, Malmivaara A, Chou R, et al; Editorial Board of the Cochrane Back, Neck Group. 2015 updated method guideline for systematic reviews in the Cochrane back and neck group. Spine (Phila Pa 1976). 2015;40 (21):1660-1673. doi:10.1097/BRS.0000000000001061.

54. Manchikanti L, Hirsch JA, Cohen SP, et al. Assessment of methodologic quality of randomized trials of interventional techniques: development of an interventional pain management specific instrument. Pain Physician. 2014;17(3):E263-E290. doi:10.36076/ppj.2014/17/E263

55. Manchikanti L, Falco FJE, Benyamin RM, Kaye AD, Boswell MV, Hirsch JA. A modified approach to grading of evidence. Pain Physician. 2014;17(3):E319-E325. doi:10.36076/ppj.2014/17/E319

56. Çetin A, Yektaş A. Evaluation of the short- and long-term effectiveness of pulsed radiofrequency and conventional radiofrequency performed for medial branch block in patients with lumbar facet joint pain. Pain Res Manag. 2018;43(2):76-80.

57. Civelek E, Cansever T, Kabatas S, et al. Comparison of effectiveness of facet joint injection and radiofrequency denervation in chronic low back pain. Turk Neurosurg. 2012;22(2):200-206.

58. Cohen SP, Williams KA, Kurihara C, et al. Multicenter, randomized, comparative cost-effectiveness study comparing 0,1 , and 2 diagnostic medial branch (facet joint nerve) block treatment paradigms before lumbar facet radiofrequency denervation. Anesthesiology. 2010;113(2):395-405. doi:10.1097/ALN.0b013e3181e33ae5

59. Lakemeier S, Lind M, Schultz W, et al. A comparison of intraarticular lumbar facet joint steroid injections and lumbar facet joint radiofrequency denervation in the treatment of low back pain: a randomized, controlled, double-blind trial. Anesth Analg. 2013;117 (1):228-235. doi:10.1213/ANE.0b013e3182910c4d

60. Dobrogowski J, Wrzosek A, Wordliczek J. Radiofrequency denervation with or without addition of pentoxifylline or methylprednisolone for chronic lumbar zygapophysial joint pain. Pharmacol Rep. 2005;57(4):475-480.

61. Juch JNS, Maas ET, Ostelo RWJG, et al. Effect of radiofrequency denervation on pain intensity among patients with chronic low back pain: the mint randomized clinical trials. JAMA. 2017;318(1):68-81.

62. McCormick ZL, Choi H, Reddy R, et al. Randomized prospective trial of cooled versus traditional radiofrequency ablation of the medial branch nerves for the treatment of lumbar facet joint pain. Reg Anesth Pain Med. 2019;44(3):389-397. doi:10.1136/rapm-2018-000035

63. Moon JY, Lee PB, Kim YC, Choi SP, Sim WS. An alternative distal approach for the lumbar medial branch radiofrequency denervation: a prospective randomized comparative study. Anesth Analg. 2013;116 (5):1133-1140. doi:10.1213/ANE.0b013e31828b35fe

64. Moussa WMM, Khedr W. Percutaneous radiofrequency facet capsule denervation as an alternative target in lumbar facet syndrome. Clin Neurol Neurosurg. 2016;150:96-104. doi:10.1016/j.clineuro.2016.09.004

65. Nath S, Nath CA, Pettersson K. Percutaneous lumbar zygapophysial (facet) joint neurotomy using radiofrequency current, in the management of chronic low back pain: a randomized double-blind trial. Spine (Phila Pa 1976). 2008;33(12):1291-1297; discussion 1298. doi:10.1097/BRS.0b013e31817329f0

66. Song K, Li Z, Shuang F, et al. Comparison of the effectiveness of radiofrequency neurotomy and endoscopic neurotomy of lumbar medial branch for facetogenic chronic low back pain: a randomized controlled trial. World Neurosurg. 2019;126:e109-e115. doi:10.1016/ j.wneu.2019.01.251 
67. Tekin I, Mirzai H, Ok G, Erbuyun K, Vatansever D. A comparison of conventional and pulsed radiofrequency denervation in the treatment of chronic facet joint pain. Clin J Pain. 2007;23(6):524-529. doi:10.1097/AJP.0b013e318074c99c

68. van Wijk RMAW, Geurts JWM, Wynne HJ, et al. Radiofrequency denervation of lumbar facet joints in the treatment of chronic low back pain: a randomized, double-blind, sham lesion-controlled trial. Clin J Pain. 2005;21(4):335-344. doi:10.1097/01.ajp.0000120792.69705.c9

69. van Kleef M, Barendse GA, Kessels A, Voets HM, Weber WE, de Lange S. Randomized trial of radiofrequency lumbar facet denervation for chronic low back pain. Spine (Phila Pa 1976). 1999;24 (18):1937-1942. doi:10.1097/00007632-199909150-00013

70. van Tilburg CWJ, Stronks DL, Groeneweg JG, Huygen FJPM. Randomised sham-controlled double-blind multicentre clinical trial to ascertain the effect of percutaneous radiofrequency treatment for lumbar facet joint pain. Bone Joint J. 2016;98-B(11):1526-1533. doi:10.1302/0301-620X.98B11.BJJ-2016-0379.R2

71. Vorobeychik Y, Stojanovic MP, McCormick ZL. Radiofrequency denervation for chronic low back pain. JAMA. 2017;318(22):2254 2255. doi:10.1001/jama.2017.16386

72. Rimmalapudi V, Buchalter J, Calodney A. Radiofrequency denervation for chronic low back pain. JAMA. 2017;318(22):2255-2256. doi:10.1001/jama.2017.16378

73. Kao MC, Leong MS, Mackey S. Radiofrequency denervation for chronic low back pain. JAMA. 2017;318(22):2256. doi:10.1001/ jama.2017.16382

74. Kapural L, Provenzano D, Narouze S, et al. Effect of radiofrequency denervation on pain intensity among patients with chronic low back pain: the Mint randomized clinical trials. JAMA. 2017;318(1):68-81 doi:10.1001/jama.2017.7918

75. van Kuijk SMJ, Van Zundert J, Hans G, et al. Flawed study design and incorrect presentation of data negatively impact potentially useful interventional treatments for patients with low back pain: a critical review of JAMA's MinT Study. Pain Pract. 2018;18(3):292-295. doi:10.1111/papr.12673

76. Argyriou AA, Anastopoulou GG, Bruna J. Inconclusive evidence to support the use of minimally-invasive radiofrequency denervation against chronic low back pain. Ann Transl Med. 2018;6(7):127. doi:10.21037/atm.2018.01.23

77. Provenzano DA, Buvanendran A, de León-casasola O, Narouze S, Cohen SP. Interpreting the MINT randomized clinical trials: let us stick to the facts. Reg Anesth Pain Med. 2020;45(1):84-86. doi:10.1136/rapm-2019-100905

78. Provenzano DA, Buvanendran A, de León-casasola OA, Narouze S, Cohen SP. Interpreting the MINT randomized trials evaluating radiofrequency ablation for lumbar facet and sacroiliac joint pain: a call from ASRA for better education, study design, and performance. Reg Anesth Pain Med. 2018;43(1):68-71. doi:10.1097/AAP.0000000000000699

79. Leggett LE, Soril LJ, Lorenzetti DL, et al. Radiofrequency ablation for chronic low back pain: a systematic review of randomized controlled trials. Pain Res Manag. 2014;19(5):e146-153. doi:10.1155/2014/834369

80. Poetscher AW, Gentil AF, Lenza M, Ferretti M. Radiofrequency denervation for facet joint low back pain: a systematic review. Spine (Phila Pa 1976). 2014;39(14):E842-E849. doi:10.1097/ BRS.0000000000000337

Journal of Pain Research

\section{Publish your work in this journal}

The Journal of Pain Research is an international, peer reviewed, open access, online journal that welcomes laboratory and clinical findings in the fields of pain research and the prevention and management of pain Original research, reviews, symposium reports, hypothesis formation and commentaries are all considered for publication. The manuscript

Submit your manuscript here: https://www.dovepress.com/journal-of-pain-research-journal
81. Manchikanti L, Knezevic NN, Sanapati J, Kaye AD, Sanapati MR, Hirsch JA. Is epidural injection of sodium chloride solution a true placebo or an active control agent? A systematic review and metaanalysis. Pain Physician. 2021;24(1):41-59.

82. Manchikanti L, Knezevic NN, Sanapati MR, Boswell MV, Kaye AD, Hirsch JA. Effectiveness of percutaneous adhesiolysis in managing chronic central lumbar spinal stenosis: a systematic review and metaanalysis. Pain Physician. 2019;22(6):E523-E550. doi:10.36076/ppj/ 2019.22.E523

83. Manchikanti L, Knezevic NN, Sanapati SP, Sanapati MR, Kaye AD, Hirsch JA. Is percutaneous adhesiolysis effective in managing chronic low back and lower extremity pain in post-surgery syndrome: a systematic review and meta-analysis. Curr Pain Headache Rep. 2020;24(6):30. doi:10.1007/s11916-020-00862-y

84. Manchikanti L, Soin A, Boswell MV, Kaye AD, Sanapati M, Hirsch JA. Effectiveness of percutaneous adhesiolysis in post lumbar surgery syndrome: a systematic analysis of findings of systematic reviews. Pain Physician. 2019;22(4):307-322. doi:10.36076/ppj/2019.22.307

85. Cappola AR, FitzGerald GA. Confluence, not conflict of interest: name change necessary. JAMA. 2015;314(17):1791-1792. doi:10.10 01/jama.2015.12020

86. Prusova K, Churcher L, Tyler A, Lokugamage U. Royal college of obstetricians and gynaecologists guidelines: how evidence-based are they? J Obstet Gynaecol. 2014;34(8):706-711. doi:10.3109/014436 15.2014.920794

87. Clark J, Nijs J, Yeowell G, Goodwin PC. What are the predictors of altered central pain modulation in chronic musculoskeletal pain populations? A systematic review. Pain Physician. 2017;20(6):487-500. doi:10.36076/ppj.2017.20.5.487

88. Schwartz D. Evidence-based medicine is NOT the holy grail (Share) - new improved. Available from: https://www.linkedin.com/pulse/ evidence-based-medicine-holy-grail-david-schwartz. Accessed May $11,2021$.

89. Kaye AD, Manchikanti L, Novitch MB, et al. Responsible, safe, and effective use of antithrombotics and anticoagulants in patients undergoing interventional techniques: American Society of Interventional Pain Physicians (ASIPP) guidelines. Pain Physician. 2019;22(1S): S75-S128. doi:10.36076/ppj/2019.22.s75

90. Navani A, Manchikanti L, Albers SL, et al. Responsible, safe, and effective use of biologics in the management of low back pain: American Society of Interventional Pain Physicians (ASIPP) guidelines. Pain Physician. 2019;22(1S):S1-S74. doi:10.36076/ppj/2019. 22.s1

91. Howick J. The evidence-based medicine renaissance: holy grail or poisoned chalice? BMC Blog Network. 2014. Available from: https:// blogs.biomedcentral.com/on-medicine/2014/07/03/the-evidencebased-medicine-renaissance-holy-grail-or-poisoned-chalice/.

92. Rysavy M. Evidence-based medicine: a science of uncertainty and an art of probability. Virtual Mentor. 2013;15(1):4-8.

93. Hickey S, Roberts H. Evidence based medicine: neither good evidence nor good medicine. Orthomol Med News Service; 2011. Available from http://orthomolecular.org/resources/omns/v07n15. shtml management system is completely online and includes a very quick and fair peer-review system, which is all easy to use. Visit http:// www.dovepress.com/testimonials.php to read real quotes from published authors. 